\title{
20. RECONSOLIDATION TESTS AND SONIC VELOCITY MEASUREMENTS OF CLAY-RICH SEDIMENTS FROM THE NANKAI TROUGH ${ }^{1}$
}

\author{
Daniel E. Karig²
}

\begin{abstract}
Uniaxial reconsolidation tests were conducted on samples from four whole-round cores of similar hemipelagic silty mudstones from the Shikoku Basin sequence recovered at DSDP Site 582 and ODP Site 808. Two cores from Site 808 were from below the décollement, in the prism toe, and two from Site 582 were from the undeformed trench wedge. The objectives of testing included the estimation of maximum past consolidation stress, the in-situ stress, the exploration of relationships between physical properties and mechanical state of the naturally consolidated mudstones, and comparison of the behavior of these natural sediments with similar but experimentally consolidated mudstone. Testing also determined the effect of pressure between laboratory ( 1 bar) and in-situ conditions on seismic velocity and on porosity.

On the basis of their yield stresses $\left(\sigma_{c}{ }^{\prime}\right)$, samples from Site 582 were overconsolidated, whereas those from Site 808 were highly underconsolidated. The apparent overconsolidation at Site 582 is attributed to incipient cementation, which contributes strength and stiffness to the sediment. Porosity in these samples was much higher than that in the experimentally consolidated analog at the same $\sigma_{v}{ }^{\prime}$, which probably reflects higher than hydrostatic pore pressure. However, the effect of excess pore pressure on $\sigma_{c}{ }_{c}^{\prime}$ is masked by that of cementation.

In part, the underconsolidation at Site 808 is thought to reflect inhibited drainage, primarily occurring as these sediments were subducted beneath the tip of the décollement. The extreme apparent underconsolidation of the sample closest to the décollement is attributed to a reduction of $\sigma_{c}{ }^{\prime}$ caused by destruction of cementation, possibly by isotropic stress pulses of high pore-fluid pressure.

The enhanced cementation at Site 582 relative to that at Site 808 , which behaves similarly to the uncemented, experimentally consolidated mudstone, results in much higher constrained moduli and higher seismic velocities at equivalent porosities. This demonstrates that velocity-porosity relationships are strongly influenced by very subtle differences in sediment properties. Seismic velocities increased between $5 \%$ and $10 \%$ between laboratory and in-situ pressures. Most of this increase reflects crack closing at low pressure. Porosity rebound at both sites was from $<1 \%-2 \%$, far less than for the experimentally consolidated sediment or than was predicted from published values for mudstones.
\end{abstract}

\section{INTRODUCTION}

The mechanical behavior of clay-rich sediments, particularly at conditions of higher stresses and lower porosities, is probably the least known among the common sedimentary rocks. In large part this stems from their low permeability, so that mechanical behavior tests must be of long duration using specialized testing equipment. Nevertheless, data from low-porosity, clay-rich strata are very important, as this sediment type will account for an increasing fraction of ODP cores as progressively deeper holes are drilled into thick sediment sections.

Most of the sediment recovered from Site 808, from the units beneath the trench fill, fall into this category. From a depth of about $600 \mathrm{mbsf}$, almost to the base of the section, the sediments consist of fairly uniform clayey silts and silty clays with porosities between $30 \%$ and $40 \%$ (Taira, Hill, Firth et al., 1991). As such they comprise a good data set that illustrates changes in physical properties and mechanical parameters related to the stress history to which these sediments have been subjected. Conversely, determination of physical properties and some mechanical parameters in these sediments can be used to constrain the state of stress in Hole $808 \mathrm{C}$. In fact, given the problems encountered with downhole measurements at this site, laboratorybased techniques constitute a primary means to this end for Leg 131.

The testing undertaken in this study employed our computercontrolled high-stress triaxial cell, in which core samples could be subjected to a wide variety of stress paths. In addition, acoustic transducers in the platens allowed the determination of compressional

\footnotetext{
${ }^{1}$ Hill, L.A., Taira, A., Firth, J.V., et al., 1993. Proc. ODP, Sci. Results, 131: College Station, TX (Ocean Drilling Program).
} U.S.A. seismic velocities $\left(V_{p}\right)$ in the vertical direction at any time during the testing sequence. Because the low permeability required very low strain rates, each test sequence included several subtests to maximize data from each sample.

Samples for this study were restricted to clay-rich sediments from depths where the cores were macroscopically undisturbed by the drilling process. Clay-rich lithologies were chosen for study because these are the dominant sediment type and display the most sensitive strain responses to applied stress. In addition, the results of tests on these sediments are compared with our earlier test results on a suite of clay-rich sediments with similar lithologic characteristics that were experimentally consolidated (Karig and Hou, 1992). Six 15-17 cm long, whole-round samples were collected between depths of 386 and 1099 mbsf from Hole $808 \mathrm{C}$ for this testing; four from above the décollement and two from below. These samples were selected on the core rack for minimum disturbance and were used first for anelastic strain recovery (ASR) tests (Taira, Hill, Firth et al., 1991). After completion of these nondestructive tests the cores were sealed in plastic tubes, waxed, and stored in a refrigerated humid environment. Only the deepest two cores from Site 808 have been used to date in this test series (Table 1), which is still in progress.

One aspect of mechanical testing planned for samples from Leg 131 was to compare the strain and states of stress between the uniaxially consolidated sediment of the trench wedge with their deformed analogs in the prism toe. Because no hole was drilled in the trench wedge near Site 808 , and because we still had a suite of six whole-round samples from the Nankai Trench wedge at DSDP Site 582 (Fig. 1), the two deepest and consolidated samples were included in the testing program (Table 1). These cores, which had been refrigerated in a humid environment, were still in excellent condition and proved to be mineralogically very similar to those tested from Site 808 (Fig. 2). 
Table 1. Principal values and results of sample tests.

\begin{tabular}{lcccc}
\hline Sample & $582-63-2$ & $582-73-1$ & $808-74-2$ & $808-85-1$ \\
Test Number & $\mathrm{T}-38$ & $\mathrm{~T}-36$ & $\mathrm{~T}-33$ & $\mathrm{~T}-39$ \\
Depth $(\mathrm{mbsf})$ & 644 & 744 & 1004 & 1098 \\
$\sigma_{c}^{\prime}(\mathrm{MPa})$ & $6.9 \pm 0.2$ & $9.0 \pm 0.5$ & $2.9 \pm 0.2$ & $5.5 \pm 0.3$ \\
$\sigma_{v h^{\prime}}(\mathrm{MPa})$ & 5.6 & 6.4 & 9.2 & 10.4 \\
$\sigma_{v^{*}}(\mathrm{MPa})$ & 1.8 & 2.4 & $<2.9$ & $\leq 5.5$ \\
$K_{0}$ & 0.65 & - & 0.68 & 0.60 \\
$\eta @ \sigma_{v}^{\prime}=0$ & 0.525 & 0.501 & 0.33 & 0.312 \\
$\eta @ \sigma_{v}^{\prime}=\sigma_{c}^{\prime}$, & 0.508 & 0.479 & 0.31 & 0.292 \\
$\eta @ \sigma_{v}^{\prime}=\sigma_{v^{\prime}}$ & 0.52 & 0.493 & 0.31 & 0.29 \\
$V_{p} @ \sigma_{v}^{\prime}=0$ & 1.692 & 1.78 & - & 1.858 \\
$V_{p} @ \sigma_{v}^{\prime}=\sigma_{c}^{\prime}$ & 1.88 & 1.99 & - & 2.12 \\
$V_{p} @ \sigma_{v}^{\prime}=\sigma_{v}^{\prime}$ & 1.79 & 1.91 & - & $\leq 2.12$ \\
$k\left(\mathrm{~m}^{2}\right)$ & $1.3 \times 10^{-15}$ & $4.4 \times 10^{-15}$ & - & $2.94 \times 10^{-16}$ \\
\hline & & & & \\
\hline & & & &
\end{tabular}

Because of the lack of downhole stress data from Leg 131, the estimation of on the in-situ vertical effective stress $\left(\sigma_{v^{*}}\right)$ became a principal objective of the test program (see Table 2 for symbols and definitions of variables used in this paper). Reconsolidation tests do not allow the direct determination of $\sigma_{y^{*}}$ but do generate yield stress $\left(\sigma_{c}{ }^{\prime}\right)$, which, under appropriate conditions, approximate the maximum vertical effective stress to which a sediment has been subjected. This state marks the yield point separating elastic from plastic mechanical behavior, and should be manifested by changes in the response of many parameters. All the tests of this series employed uniaxial (vertical) strain paths because the sediments both at Site 582 and beneath the décollement at Site 808 were thought to have undergone only uniaxial consolidation. Integrated into this test program was a comparison of the mechanical behavior of these naturally consolidated sediments with that of similar mudstones that had previously been experimentally consolidated in our laboratory.

Another objective was the determination of the porosity $(\eta)$ and seismic velocity $\left(V_{p}\right)$ at $\sigma_{v^{*}}$. More specifically, the pressure corrections were sought that should be applied to laboratory measurements so that they can be compared with in-situ or log measurements. In addition, estimates of intergranular permeability $(k)$ were made during the saturation phase of most tests.

\section{TESTING PROCEDURES}

Each whole-round core sample was to have been subsampled for up to four separate tests. Cracking of the material during storage or during the attempt to core the samples limited this goal, especially before experience was acquired in handling the material. The initial,

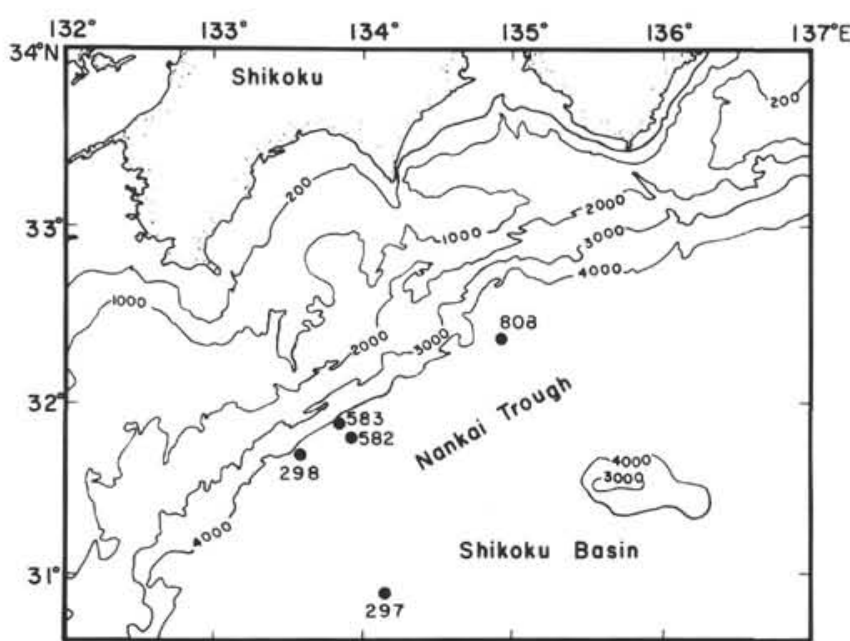

Figure 1. Location of DSDP Site 582 and ODP Site 808, from which the samples for this study were recovered.
Table 2. Explanation of symbols.

\begin{tabular}{ll}
\hline$\sigma_{v}{ }^{\prime}$ & Effective vertical stress (in the tests) \\
$\sigma_{h}{ }^{\prime}$ & Effective horizontal stress \\
$\sigma_{m}^{\prime}$ & Effective mean stress $\left[\left(\sigma_{v}^{\prime}+2 \sigma_{h}\right) / 3\right]$ \\
$\Delta \sigma$ & Differential stress $\left[\sigma_{v}^{\prime}-\sigma_{h}^{\prime}\right]$ \\
$\sigma_{c}^{\prime}, \quad$ Yield stress (in the tests) \\
$\sigma_{v h}, \quad$ Effective vertical stress (in-situ), assuming hydrostatic pore pressure \\
$\sigma_{v}^{\prime}$ & Effective vertical stress (in-situ) \\
$K_{0}$ & Stress ratio $\left[\sigma_{h}^{\prime} / \sigma_{y}^{\prime}\right]$ during plastic, uniaxial (vertical) consolidation \\
$\varepsilon_{v}$ & Vertical strain (in the tests) \\
$z$ & Depth in meters below sea floor (mbsf) \\
$\eta$ & Sediment porosity \\
$V_{p}$ & Compressional seismic velocity in the vertical direction \\
$k$ & Permeability (hydraulic conductivity) \\
$\rho_{b}$ & Sediment bulk density \\
$\lambda$ & Fluid overpressure ratio (see equation 2) \\
$g$ & Gravitational acceleration \\
\hline
\end{tabular}

and primary subsample for this study was a cylindrical core, with a vertical axis, $50 \mathrm{~mm}$ in length and $30 \mathrm{~mm}$ in diameter, used for uniaxial consolidation. The three subsequent subsamples for triaxial tests, if taken, were $50 \mathrm{~mm}$ long and $20 \mathrm{~mm}$ in diameter. These dimensions were determined by the diameter of ODP cores and by the requirement of triaxial testing that sample lengths be at least twice as great as their diameters. Only the consolidation testing, which was divided into two to three phases, is described in this paper.

\section{Phase 1-Resaturation}

Exsolution of dissolved gas in the pore spaces of some ODP cores can cause them to be only partly saturated, and the samples must be fully saturated before water volume change can be used as a measure of volume strain. Saturation was accomplished by placing the sample under a hydrostatic pressure of $1 \mathrm{MPa}$ and a differential pore pressure from one end to the other of approx $0.4 \mathrm{MPa}$, and maintaining this pressure gradient until fluid flows at a constant rate out the lowpressure end. The fluid used during this and all phases of the testing was a 35-ppt $\mathrm{NaCl}$ solution intended to simulation a seawater pore fluid. Fluid flow through the sample was measured by a linear variable displacement transformer (LVDT) in parallel with the fluid pressure intensifier cylinder. This phase of the test constituted a constant-head permeability test.

\section{Phase 2-Equilibration}

Following resaturation, which takes a day or more, the sample is brought to a uniform hydrostatic stress state at a total confining pressure of $2 \mathrm{MPa}$ and a pore pressure of $1 \mathrm{MPa}$, the latter to ensure
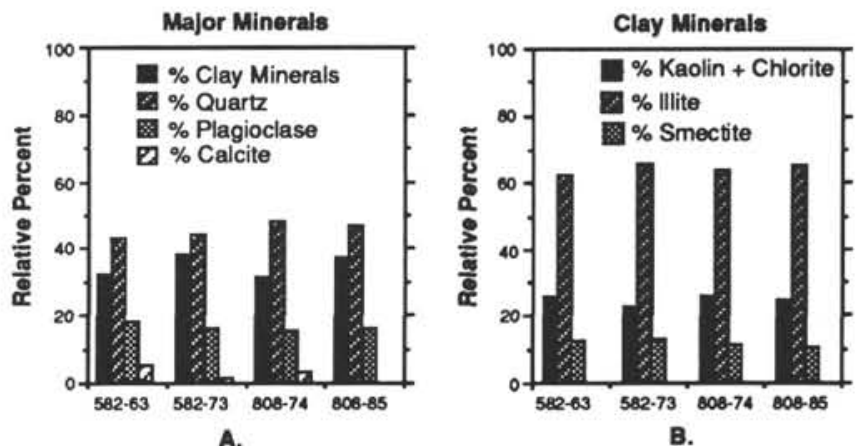

Figure 2. Mineralogy of samples used in the test program based on bulk powder XRD analyses run by M.B. Underwood. Histogram A shows the relative abundance of the major minerals, whereas Histogram $\mathbf{B}$ displays the relative abundance of clay minerals. Both show that the mineralogy at both sites is very similar. 
that all remaining gases in the system are in solution. This phase usually takes 1 to 2 days.

\section{Phase 3-Reconsolidation}

When the sample shows no further significant change in volume, the uniaxial reconsolidation phase is begun. This stress path, which requires that the cross-sectional area of the sample stay constant during application of a constantly increasing axial stress, is generated by an algorithm that adjusts the confining pressure and the axial load proportionately to the rate of change of cross-sectional area. This "buffering" prevents oscillation of the applied stresses. Vertical stress rates $\left(\partial \sigma_{v}^{\prime} / \partial_{t}\right)$ of $1.15 \times 10^{-5} \mathrm{MPa} / \mathrm{s}$ were used in our tests and axial stress limits were set well above those expected for yield so that stress ratios in the plastic regime could be determined. Constant stress rate tests were used instead of stepwise increasing stresses to produce better definition of the yield state. This method also balanced the effects of decreasing axial strain rate in the plastic regime against those of decreasing permeability on possible excess pore-fluid pressures. Some tests had stress holds to detect possible excess pore-water pressures, but in no test did we see evidence for any. Moreover, these holds afforded us the opportunity to investigate secondary creep and its effects on stress ratio.

The LVDT's in our system are sensitive to displacements of less than $1 \mu \mathrm{m}$, but environmental factors such as electrical drift limit the accuracy to several micrometers and the resultant strain to $\pm 0.5 \times$ $10^{-5}$. Stresses from the pressure transducers and from our internal load cell are accurate to better than $0.01 \mathrm{MPa}$.

At selected time intervals ( $0.5 \mathrm{hr}$ in these tests), voltages were read by the computer from the four radial LVDT pairs, two axial LVDT's, axial load, water volume LVDT, and the confining pressure and pore-pressure sensors. In addition to being stored for later manipulations, these voltages were also converted to approximate values of all stresses and strains, and plotted in real time. In this way test progress was easily monitored and adjustments could be made immediately.

Compressional seismic velocities $\left(V_{p}\right)$ were run at selected points throughout the test, with an initial velocity measurement usually taken at $0 \mathrm{MPa}$ confining pressure for comparison with shipboard measurements. The traveltime through the sample was automatically integrated with the strain data to permit velocity determination to an accuracy within $\pm 0.01 \mathrm{~km} / \mathrm{s}$.

\section{TEST RESULTS}

Eight reconsolidation tests were run on core samples from four cores collected at DSDP/ODP Sites 582 and 808, although some were terminated before completion. The tests are described by hole, with increasing depth, rather than in order of testing.

Mechanical parameters measured included axial and radial strain (along four equally spaced azimuths), confining and pore pressure, and axial stress. To estimate the yield stress, various relationships among these variables (e.g., $\sigma_{h}{ }^{\prime}$ vs. $\sigma_{v}{ }^{\prime}, \Delta \sigma$ vs. $\varepsilon_{v}$ ) were used in addition to the the relationship between $\varepsilon_{v}$ and $\sigma_{v}{ }^{\prime}$ which is commonly relied upon in geotechnical studies (e.g., Ladd et al., 1977; Jamiolkowski et al., 1985). The yield points were picked at the point where the rate of deviation from the elastic slope began to change rapidly. In some cases (e.g., $\varepsilon_{y}$ vs. $\left.\sigma_{y}{ }^{\prime}\right)$, the plastic response can be linearized by using a semilogarithmic plot, which further constrains the choice. In other cases, however, the post-yield response is complex, with a full plastic state being reached only far beyond the yield point. A final yield stress was a qualitative best fit or mean to the picks using all the available relationships.

\section{SAMPLES FROM SITE 582}

Site 582 was drilled in the Nankai Trough several kilometers seaward of the deformation front, but about $100 \mathrm{~km}$ west of Site 808
(Fig. 1). The structural and sedimentological settings in the two areas of this trough are generally similar, with a sand-rich turbiditic trenchfill overlying hemipelagic silty clays and clay-rich silts comprising the Shikoku Basin fill. Samples used for these tests came from the upper part of the Shikoku Basin sequence.

\section{Sample 87-582-63-2 (130-150 cm), 644 mbsf}

Sample $582-63$ is an olive-gray hemipelagic bioturbated silty mudstone consisting of $32 \%$ clay minerals, $43 \%$ quartz, $17 \%$ feldspar, and $6 \%$ calcite (Fig. 2). It was recovered from a zone with several micro-normal faults that dip $50^{\circ}-80^{\circ}$ (Lundberg and Karig, 1986). Although these sediments are assumed to have been uniaxially consolidated in the trench, these normal faults imply incipient lateral extension due to very mild flexure of the downgoing plate (Lundberg and Karig, 1986).

When opened, the core was found to be broken on a $5^{\circ}-10^{\circ}$ dipping fracture about $15 \mathrm{~mm}$ from the base. A first attempt to subsample the larger piece resulted in the cracking of the sample, so that only one vertically oriented subsample was obtained for testing. Even this sample was shorter $(45 \mathrm{~mm})$ than desirable, which degraded the measurement of axial strain at higher vertical strains when rings holding the LVDT's came into contact. Several step increases and holds in the vertical stress path were incorporated into this test to explore creep and the effect of creep on stress ratios.

\section{Consolidation and Stress Ratios}

The elastic-plastic transition or yield point in this sample is well defined on plots of $\sigma_{h}{ }^{\prime}$ vs. $\sigma_{v}{ }^{\prime}, \varepsilon_{v}$ vs. $\sigma_{v}{ }^{\prime}$, and $\Delta \sigma$ vs. $\varepsilon_{v}$. The effective vertical stress at yield, or $\sigma_{c}$, ranges from 6.5 to $7.2 \mathrm{MPa}$, with the most sharply defined break on the $\Delta \sigma$ vs. $\varepsilon_{v}$ plot at $6.9 \mathrm{MPa}$ (Fig 3).

The stress ratio $\left(\sigma_{h}{ }^{\prime} / \sigma_{v}{ }^{\prime}\right)$ during initial reconsolidation, which reflects an elastic response, is about 0.10 . This is a reasonable value for a silty clay of this porosity, but after the sample passed through the yield point, this ratio went to values of greater than 1 , which is much higher than expected for the plastic regime. With a further increase in $\sigma_{v}{ }^{\prime}$ during testing, the stress ratio became constant at 0.65 , which is almost identical to the $K_{o}$ value of our experimentally consolidated silty clay (Karig and Hou, 1992).

A step increase in $\sigma_{v}{ }^{\prime}$ from $2 \mathrm{MPa}$ to $3.5 \mathrm{MPa}$, well inside the elastic domain, showed no or very little vertical strain (creep) and no change in $\sigma_{h}{ }^{\prime}$, indicating that the constant stress rate technique was equivalent to step loading. However, at a $\sigma_{y}^{\prime}$ of $9.4 \mathrm{MPa}$, just above the yield stress, a 50 -hr stress hold resulted in significant axial creep and a 0.7-MPa increase in $\sigma_{h}{ }^{\prime}$. On the other hand, another stress hold farther into the plastic regime, at $\sigma_{v}{ }^{\prime}=17 \mathrm{MPa}$, resulted in very little creep and no change in $\sigma_{h}{ }^{\prime}$.

\section{Porosity}

The initial porosity of this sample, using measured bulk density and grain density of $52.1 \%$ from Bray and Karig (1986), is significantly greater than the $48 \%-49 \%$ porosities measured on board ship for nearby samples. This might have reflected less-saturated conditions for our long-stored sample, but the water content of our sample $(0.37)$ is significantly greater than those of the two shipboard measurements on cores from the same section, indicating that sample dehydration over the years was not the cause of an apparent porosity increase. Moreover, this water content and wet volumes before and after the test, together with measured grain density (Bray and Karig, 1986), confirms that our samples were initially saturated.

The most reliable porosities during the test were obtained by back-calculation from the final conditions using measured volume strains. These data show that the porosity at yield was $50.8 \%$ and that the porosity decrease from laboratory to yield states was $1.3 \%$. Although the porosities measured on our sample differ from ship- 

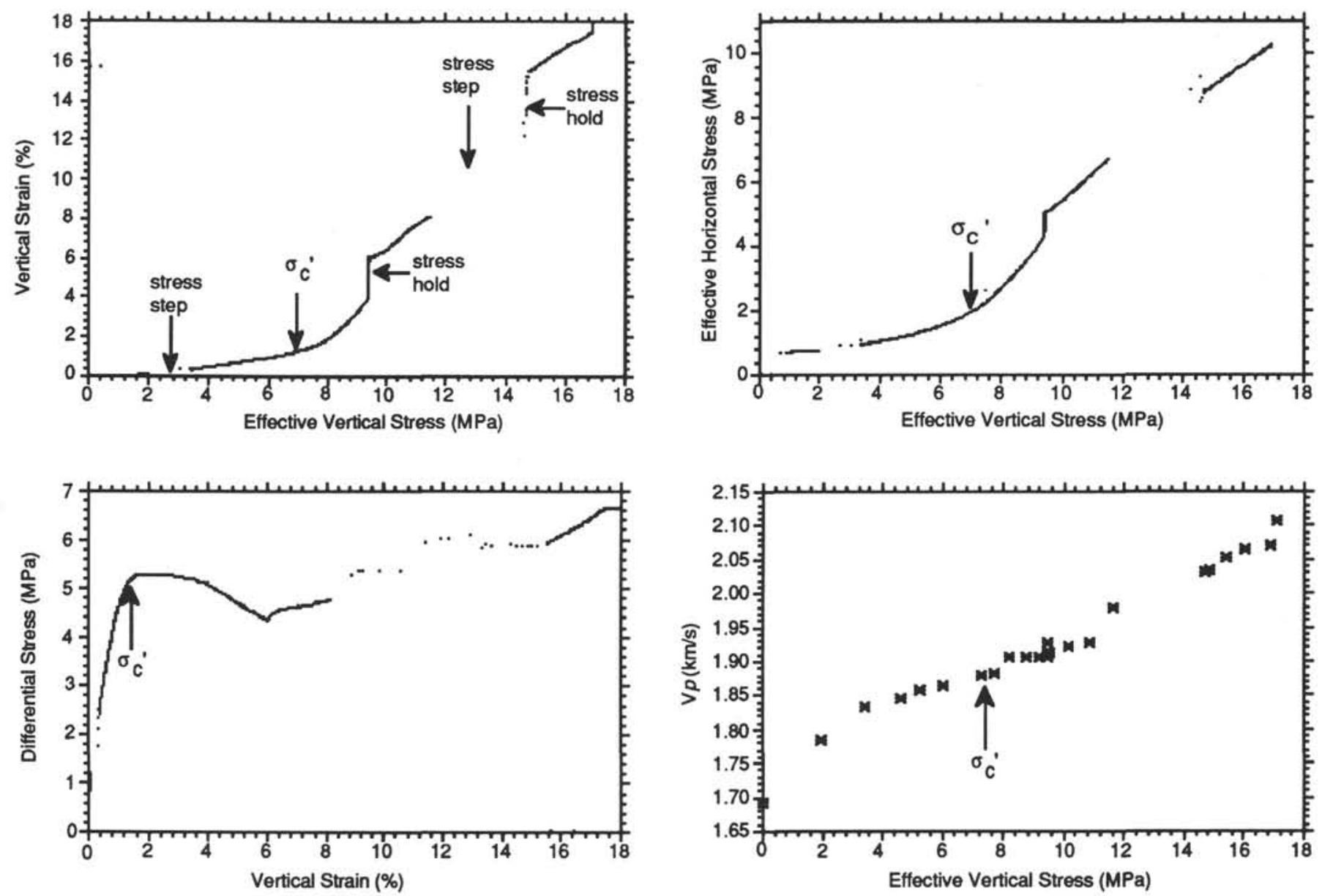

Figure 3. Representative relationships of mechanical parameters and physical properties for consolidation test (T-38) on Sample 582-63-2. The curves consist of closely spaced data points. Yield stress $\left(\sigma_{c}^{\prime}\right)$ and the several stress steps and holds are also indicated.

board values, our rebound value should be applicable because it is a porosity difference.

\section{Permeability}

Intergranular permeability was estimated during the initial saturation phase by recording the volume flow rate into the sample over a $15-$ hr period during which the flow rate was constant. With a confining pressure of $0.69 \mathrm{MPa}$ and a differential pore pressure of 0.413 $\mathrm{MPa}$, the sample was near a mean stress of $0.5 \mathrm{MPa}$. The calculated permeability at that condition is $1.3 \times 10^{-15} \mathrm{~m}^{2}$.

\section{Sonic Velocity}

A suite of $27 V_{p}$ measurements was collected during the saturation, reconsolidation, and consolidation phases of testing. The vertical seismic velocity through the sample at 1 bar (laboratory conditions) was $1.692 \mathrm{~km} / \mathrm{s}$, which is significantly below the $1.82 \mathrm{~km} / \mathrm{s}$ velocity recorded on board ship for samples near that depth. Velocities in our sample show an initial rapid increase with axial stress, but this rate of increase becomes roughly constant at $0.13 \mathrm{~km} / \mathrm{s} \cdot \mathrm{MPa}$ to the yield stress or slightly above. In the plastic regime the velocity also increases with axial stress, at a roughly constant but larger rate $(0.24 \mathrm{~km} / \mathrm{s} \cdot \mathrm{MPa})$.

\section{Sample 87-582-73-1 (68-84 cm), 744 mbsf}

Core $87-582-73$, collected from the bottom of Hole 582B, is a slightly laminated hemipelagic silty clay, consisting of $37 \%$ clay minerals, $44 \%$ quartz, $16 \%$ feldspar, and $2 \%$ calcite (Fig. 2). No structural features were mentioned in (Lundberg and Karig, 1986), but when opened, the sample had a low-angle $\left(20^{\circ}\right)$ fracture about $100 \mathrm{~mm}$ above the base, with crude down-dip grooves. Attempts to subsample the pieces caused two additional fractures to open, both of which were approximately coplanar with the first and also with faint down-dip grooves. Only a single short vertical subsample, approximately $42 \mathrm{~mm}$ long, could be salvaged from this core.

\section{Consolidation and Stress Ratio}

Uniaxial reconsolidation of this sample produced a high quality data set, but the yield stress is less well-defined than that for the previous sample. The principal reason for this is the nonlinearity of the pre-yield (reconsolidation) part of the curves (Fig. 4). Elastic behavior should have produced linear $\sigma_{v}{ }^{\prime}-\varepsilon_{v}$ and stress ratio curves, with relatively sharp changes in slope near the yield state. The combination of all relationships that should reflect the yield point indicates that $\sigma_{v}{ }^{\prime}$ at yield is best estimated as 9.0 $\pm 0.5 \mathrm{MPa}$ (Fig. 4).

The post-yield stress ratio was relatively constant between a $\sigma_{v}{ }^{\prime}$ of 12 and $13.5 \mathrm{MPa}$ at a value of 1.23 , which is far more than expected for a uniaxially consolidated sediment. Because of this anomalous value, a subsequent reconsolidation test with the same sample was run to see if this stress ratio would return to a more "normal" value at higher $\sigma_{v}{ }^{\prime}$. Due to an inadvertent shutdown of this test, the maximum $\sigma_{y}{ }^{\prime}$ of this second test was also only $13.5 \mathrm{MPa}$, but this time the post-yield stress ratio $\left(K_{0}\right)$ was 0.887 (Fig. 4). A comparison of the two stress ratio curves shows that the second test has a more sharply 

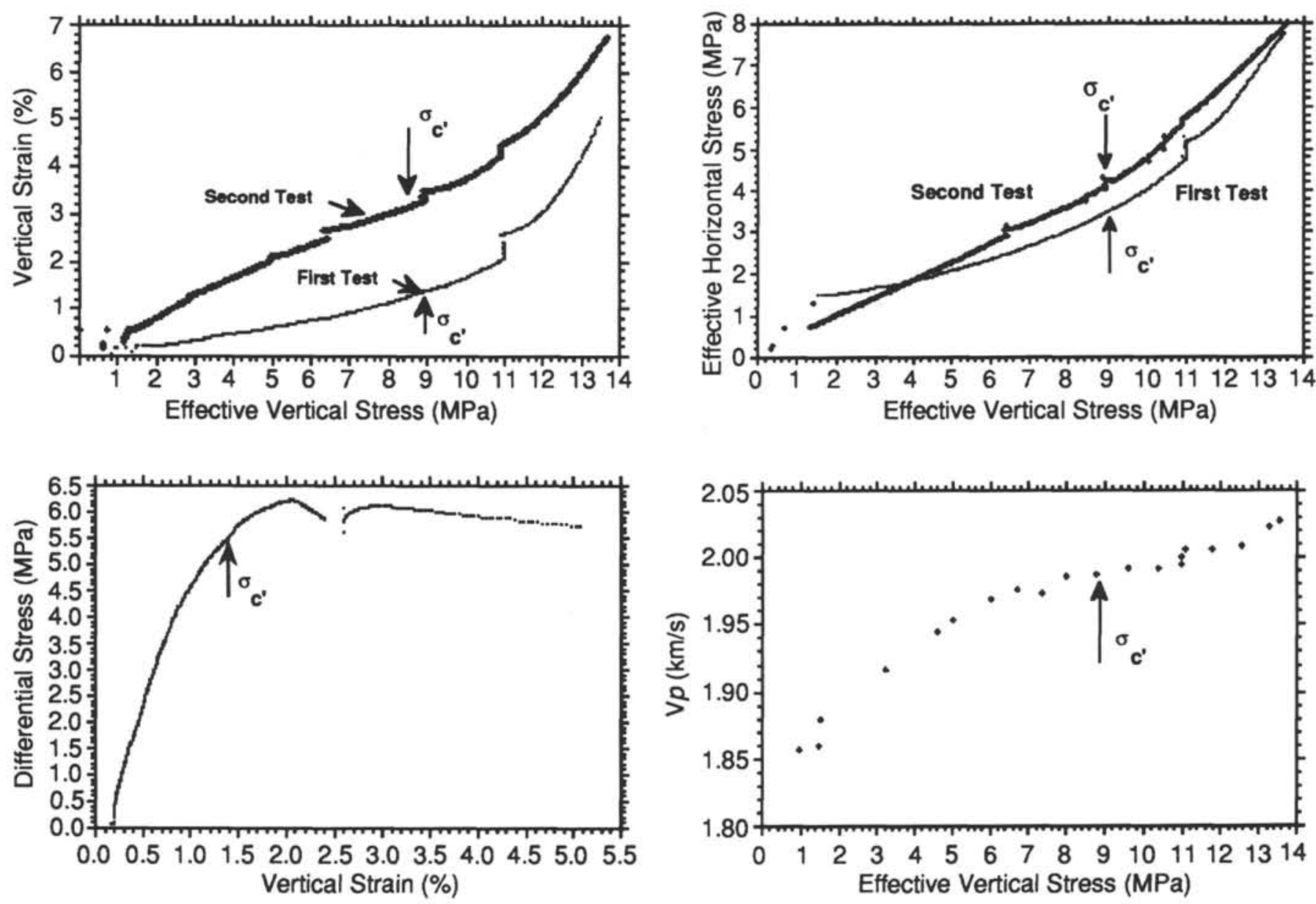

Figure 4. Representative relationships of mechanical parameters and physical properties for consolidation tests (T-36 and T-37) on Sample 582-73-1. The several stress holds in these tests are discussed in the text.

defined yield stress, also near $9 \mathrm{MPa}$, with more linear pre-and post-yield segments. At the maximum stress (13.5 MPa), the stress ratios for both tests were identical.

During both tests several axial stress holds were inserted to explore secondary consolidation (creep) and change of stress ratio as a function of mechanical state. A $20-\mathrm{hr}$ stress hold at $\sigma_{v}{ }^{\prime}=11 \mathrm{MPa}$, just into the plastic regime of the first test, resulted in a $0.5-\mathrm{MPa}$ increase in the horizontal stress and significant axial strain $(0.006)$. Upon resumption of axial stress increase, the axial strain and horizontal stress changed very little until the curve intersected the interpolation of the general curves. Several holds and steps in axial load were inserted in the second test to explore this behavior further. In the elastic range $\left(\sigma_{v}{ }^{\prime}=3 \mathrm{MPa}\right.$ and $\left.5 \mathrm{MPa}\right)$, stress holds produced very small amounts of creep but no change in stress ratio. Small inadvertent jumps in both axial and confining stress near $\sigma_{y}^{\prime}$ of $6.5 \mathrm{MPa}$ and $9 \mathrm{MPa}$, caused by a software error, produced offsets on the curve and local increases in stress ratio, but values quickly returned to the general curve and are not indicative of intrinsic mechanical behavior. A stress hold near $\sigma_{v}{ }^{\prime}$ $=10.9 \mathrm{MPa}$, just into the plastic regime, resulted in creep and in an increase in $\sigma_{h}{ }^{\prime}$.

\section{Porosity}

The initial porosity of this sample was determined using one of the subsamples that had cracked during preparation. Wet weight, wet volume, and dry weight, together with a shipboard grain density of 2.80 (Bray and Karig, 1986), demonstrated that the sample was effectively saturated. The initial porosity of $50.1 \%$ is well above the shipboard porosities of $46 \%-47 \%$ measured in cores from the same section. The porosity at $\sigma_{c}{ }^{\prime}$ was $47.9 \%$.

\section{Permeability}

This test included one of our first attempts to measure permeability and was of lower quality. The duration of this phase was too short $(5 \mathrm{hr})$ and at the end still showed a decreasing flow rate. With a mean stress of $1.15 \mathrm{MPa}$ and a differential pressure of $0.516 \mathrm{MPa}$, the minimum flow rate gave a permeability of $4.4 \times 10^{-15} \mathrm{~m}^{2}$.

\section{Sonic Velocity}

Twenty sonic measurements were acquired during this test, but the first measurement was taken only after the sample had been put under a hydrostatic load of 1.0 MPa. A linear extrapolation of the velocities to 1 bar indicates a $V_{p}$ of $1.78 \mathrm{~km} / \mathrm{s}$. This is significantly lower than the shipboard measurements of $1.86-1.87 \mathrm{~km} / \mathrm{s}$ in other samples of Core $582-73$ (Bray and Karig, 1986). $V_{p}$ increased rapidly with increasing axial stress to about 6 or $7 \mathrm{MPa}$, then more slowly to the yield stress and again more rapidly in the plastic regime. At the estimated $\sigma_{c}{ }^{\prime}$ of $9 \mathrm{MPa}, V_{p}$ is about $1.98 \mathrm{~km} / \mathrm{s}$.

\section{SAMPLES FROM SITE 808}

The samples from Site 808 below the décollement are roughly correlative with those from Site 582 in that they both represent the upper clay-rich units of the Shikoku Basin strata, but the Site 808 
samples are slightly older. XRD analyses show that the bulk mineralogy of this section is very similar at the two sites (Fig. 2).

Those samples from below the décollement at Site 808 are interpreted as having been uniaxially consolidated because of the very marked stress discontinuity at that zone, which has isolated the material beneath from horizontal tectonic stress (Taira, Hill, Firth, et al., 1991; Karig, et al., 1990). Therefore uniaxial (vertical) reconsolidation tests are probably valid reproduction of the stress history in the samples from below the décollement. This is clearly not the case above the décollement, where the sediments have been deformed under plane strain conditions and the maximum principal stress is subhorizontal.

\section{Sample 131-808C-74R-2 (114-130 cm), 1004.6 mbsf}

This sample was the closest to ( $50 \mathrm{~m}$ beneath) the décollement of this series and was also used for ASR test 5 (Taira, Hill, Firth et al., 1991). It is a moderately bioturbated, hemipelagic clayey siltstone from Unit IVb of the Shikoku Basin, consisting of $31 \%$ clay minerals, $48 \%$ quartz, $15 \%$ feldspar, and $5 \%$ calcite (Fig. 2). As this was the first test of the series, a number of technical problems had yet to be overcome, including electronic noise problems with the LVDT's and a mechanical failure of the sonic system.

\section{Consolidation and Stress Ratio}

Both the stress ratio and axial stress-axial strain curves show quite linear pre- and post-yield behavior, but the records, especially the stress ratio, are quite noisy because the apparent changes in crosssectional area of the sample produced by the LVDT noise caused oscillations in the confining pressure (Fig. 5). Moreover, there is a data shift near a $\sigma_{y}{ }^{\prime}$ of $3.5 \mathrm{MPa}$ because the output from the noisiest pair of LVDT's was removed from the algorithm for area calculation during the test, giving a sudden small shift in area. Nevertheless, the curves give reasonable and internally consistent results.

The yield stress is well defined near $2.9 \mathrm{MPa}$, which is extremely low, considering the depth from which the sample was cored. Not only the internal consistency of these curves but also the value of the post-yield stress ratio indicate that the yield stress estimated in this test is valid. The stress ratio in the plastic regime is 0.68 , which is only slightly greater than that of the experimentally consolidated sediment (Fig. 5).

\section{Porosity}

The weight and dimensions of two subsamples of this core before testing gave an apparent bulk density of $2.15 \mathrm{~g} / \mathrm{cm}^{3}$, which compared fairly well with the shipboard value of $2.17 \mathrm{~g} / \mathrm{cm}^{3}$ for samples in the same section, but the initial porosity, using the grain density obtained during shipboard measurements, was $33 \pm 0.06 \%$, significantly less than the shipboard value of $36.5 \%$ (Taira, Hill, Firth, et al., 1991). Water content measurements on samples after testing, combined with shipboard grain densities, demonstrated that this core was initially effectively saturated. The porosity at $\sigma_{c}^{\prime}$ is approximately $30 \%-32 \%$. An accurate determination is impossible because of inadequate control of differential dimensional change during unloading.

\section{Permeability}

No attempt to measure permeability was made during this first test of the series.

\section{Sonic Velocity}

Because of broken electrical leads, followed by the failure of a voltage generator, no useful sonic measurements were made during this test.

\section{Sample 131-808C-85R-1 (22-38 cm), $1098.3 \mathrm{mbsf}$}

The sample from Core 131-8086-85R was the deepest sample of the series at Site 808 and was collected $150 \mathrm{~m}$ beneath the décollement. It is a highly bioturbated, hemipelagic, clay-rich silt consisting of $37 \%$ clay minerals, $46 \%$ quartz, and $16 \%$ feldspar (Fig. 2). This sample was also used for shipboard ASR test 6 (Taira, Hill, Firth, et al., 1991).

\section{Consolidation and Stress Ratio}

The consolidation stress for this test is difficult to pick because the pre-yield curves are not very linear and because a loose electrical contact produced erratic signals near the anticipated yield state (Fig. 6). The stress response shows a pronounced change between a $\sigma_{v}{ }^{\prime}$ of 5 and $6 \mathrm{MPa}$ on various plots, with the most sharply defined change on the plot of $\Delta \sigma$ vs. $\sigma_{m}{ }^{\prime}$ near $\sigma_{v}{ }^{\prime}=5.7 \mathrm{MPa}$. The consolidation stress $\left(\sigma_{c}{ }^{\prime}\right)$ is $5.5 \pm 0.3 \mathrm{MPa}$, based on picks from all of the plots. After tightening of the loose connection, the output signals became stable and resulted in determination of a stress ratio in the plastic field $\left(K_{0}\right)$ of 0.60 .

\section{Porosity}

This sample was effectively saturated before testing based on our water content and shipboard grain-density measurements combined with volumetric calculations. The initial porosity calculated from both the initial bulk density and water content was $31.2 \%$, far less than the $34 \%$ shipboard figure measured on adjacent samples. The porosity at $\sigma_{c}^{\prime}$ was $29.2 \%$.

\section{Permeability}

The permeability determined during the saturation phase was based on a constant flow rate for over $10 \mathrm{hr}$ and led to a calculated value of $k=2.94 \cdot 10^{-16} \mathrm{~m}^{2}$ at a confining stress of $1 \mathrm{MPa}$ and a pressure differential of $0.4 \mathrm{MPa}$.

\section{Sonic Velocity}

Twenty-eight compressional sonic velocities were run during this test, from axial stresses of 0 to $10 \mathrm{MPa}$. Without stress, the velocity was $1.858 \mathrm{~km} / \mathrm{s}$, only slightly less than the raw shipboard value (not corrected for temperature effects). After a rapid rise in velocity with axial stress to about $1 \mathrm{MPa}$, the velocity rose more slowly to about $2.11 \mathrm{~km} / \mathrm{s}$ at an assumed yield stress of $5.5 \mathrm{MPa}$ and continued into the plastic regime with no obvious change in slope.

\section{INTERPRETATION}

The most striking general observation to be drawn from these tests is that the mechanical response of the samples tested from Site 582 is very different from that of the samples from below the décollement at Site 808 (Fig. 7), despite their similar mineralogy and grain-size distribution. Test results from samples at Site 582 display a sharp break in all variables near the yield state and had apparently anomalous post-yield behavior. Results from samples at Site 808 show none of the anomalous post-yield behavior and are quite similar to test results from experimentally consolidated silty clays. In addition, the samples from Site 582 have higher constrained moduli than those at Site 808, particularly when the much higher porosities of the former are taken into consideration (Fig. 8). Sharp differences in the relationship between seismic velocity and stress of the two groups can also be interpreted as a reflection of different elastic stiffnesses.

\section{Elastic Behavior}

The test samples respond elastically during the pre-yield stress path, particularly after the initially more compliant response that 

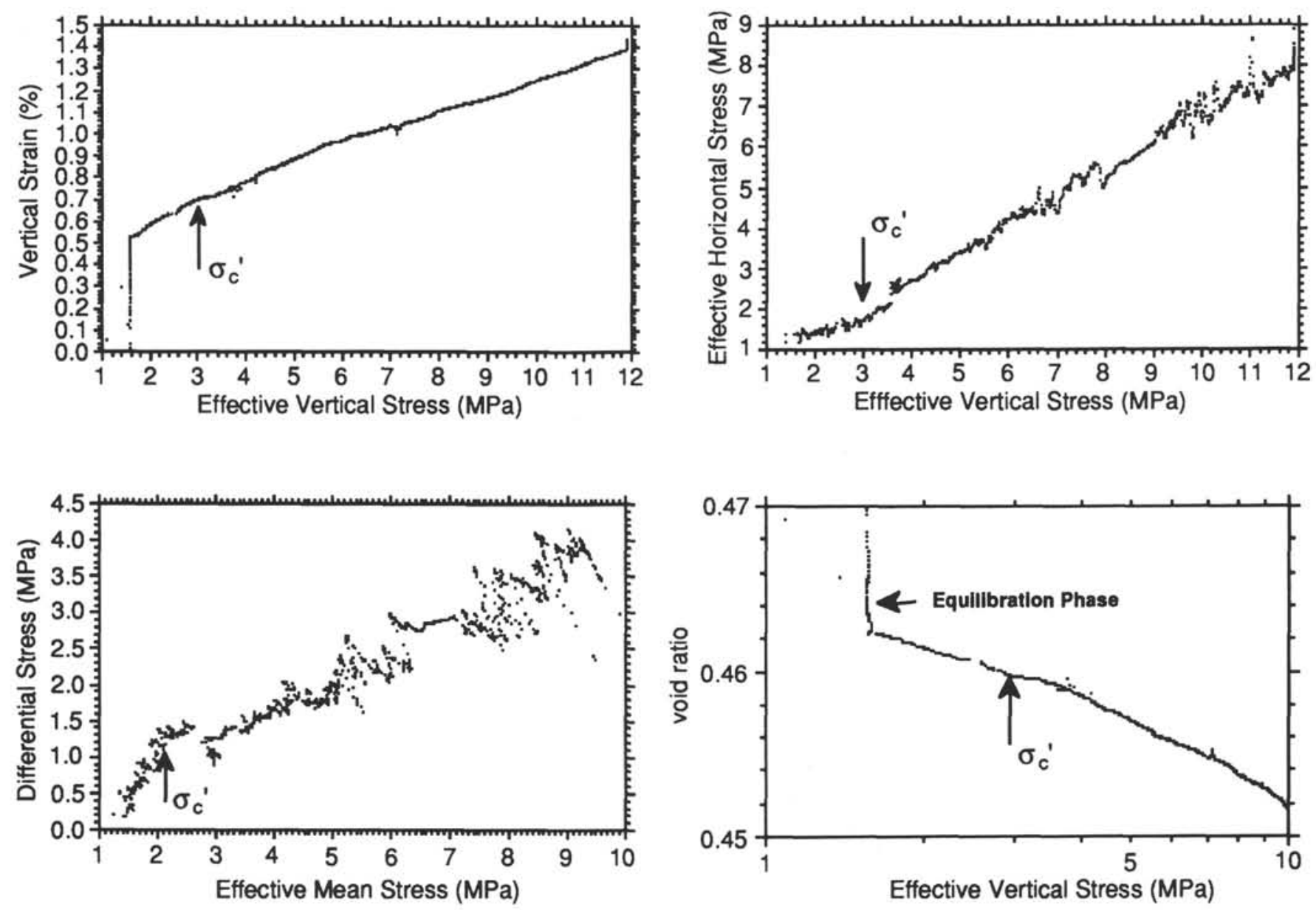

Figure 5. Representative relationships of mechanical parameters and physical properties for consolidation test (T-33) on Sample 808-74-2. The large increase in vertical strain and void ratio at $\sigma_{v}{ }^{\prime}=1.5 \mathrm{MPa}$ represents dewatering after the initial stress step. The offset in $\Delta \sigma$ at $\sigma_{m}{ }^{\prime}=2.7 \mathrm{MPa}$ was a result of removal of one LVDT signal (see text for details).

reflects the "settling" of the LVDT's and the closing of microcracks. Although the uniaxial strain of these tests precludes the direct measurement of Young's modulus (E), the axial stress/axial strain ratio during this phase, which is termed the constrained modulus $\left(E_{\mathrm{c}}\right)$, also provides a measure of compressional stiffness. Better values of $E_{\mathrm{c}}$ could be generated by cycling the axial stress through a part of the elastic regime, but the data obtained during the single loading path are sufficient for approximate and comparative values. That there was very little axial strain (creep) during stress holds in the elastic regime also supports the validity of these as elastic constants.

Magnitudes of $E_{\mathrm{c}}$ for the samples tested from Site 582 are only slightly greater than those from Site 808 , but the porosities of samples from Site 582 are much higher (Fig. 8). When $E_{\mathrm{c}}$ for both sites is plotted against porosity $(\eta)$, together with values of $E_{\mathrm{c}}$ from the experimentally consolidated sediment and with the slope of this relationship for typical clay-rich sediments, it becomes obvious that the sediments tested from Site 582 are much stiffer than those from Site 808 , which are only slightly stiffer than the experimentally consolidated mudstone at similar porosities. The much greater stiffness of the sediments from Site 582 will be shown to have major effects on the consolidation behavior as well as on $V_{p}$.

\section{Yield and Consolidation Behavior}

Perhaps the most striking difference between the mechanical behavior of samples from the two sites occurred at the yield state and during the initial post-yield stress path. The samples from Site 582 are mildly to moderately overconsolidated whereas those from beneath the décollement at Site 808 are strongly underconsolidated, at least on the basis of yield stresses. The reference state against which sample consolidation is compared is the maximum effective vertical stress to which that sample had been subjected, assuming that pore-fluid pressures were hydrostatic. At both sites the depth of core recovery is almost certainly the maximum depth to which the sample had been buried, but $\sigma_{y^{*}}{ }^{\prime}$ at that depth is not necessarily the maximum to which the sample has been subjected because pore pressures may have since increased. This is probably the case at Site 808 (see below).

Another, less precise measure of consolidation state is provided by a comparison of the sample porosity with that of a similar natural sediment subjected to $\sigma_{v h}{ }^{\prime}$ at the same depth. In this case a higher sample porosity implies underconsolidation and excess pore pressure. A combination of both approaches for the test samples reveals a complex, apparently contradictory picture of consolidation state at both sites.

The consolidation state for the samples from Site 582 was first determined from a comparison of the yield stress in the tests with $\sigma_{v h}{ }^{\prime}$. The value of $\sigma_{v h}{ }^{\prime}$ was calculated by integrating the bulk density upward from the sample depth to the sediment surface and subtracting the pressure due to a column of pore fluid of the same height:

$$
\sigma_{v h}{ }^{\prime}=g \int_{0}^{z}\left(\rho_{b}-\rho_{w}\right) \Delta z \text {, or approximately: } g \Sigma\left(\rho_{b}-\rho_{w}\right) \Delta z \text {. }
$$



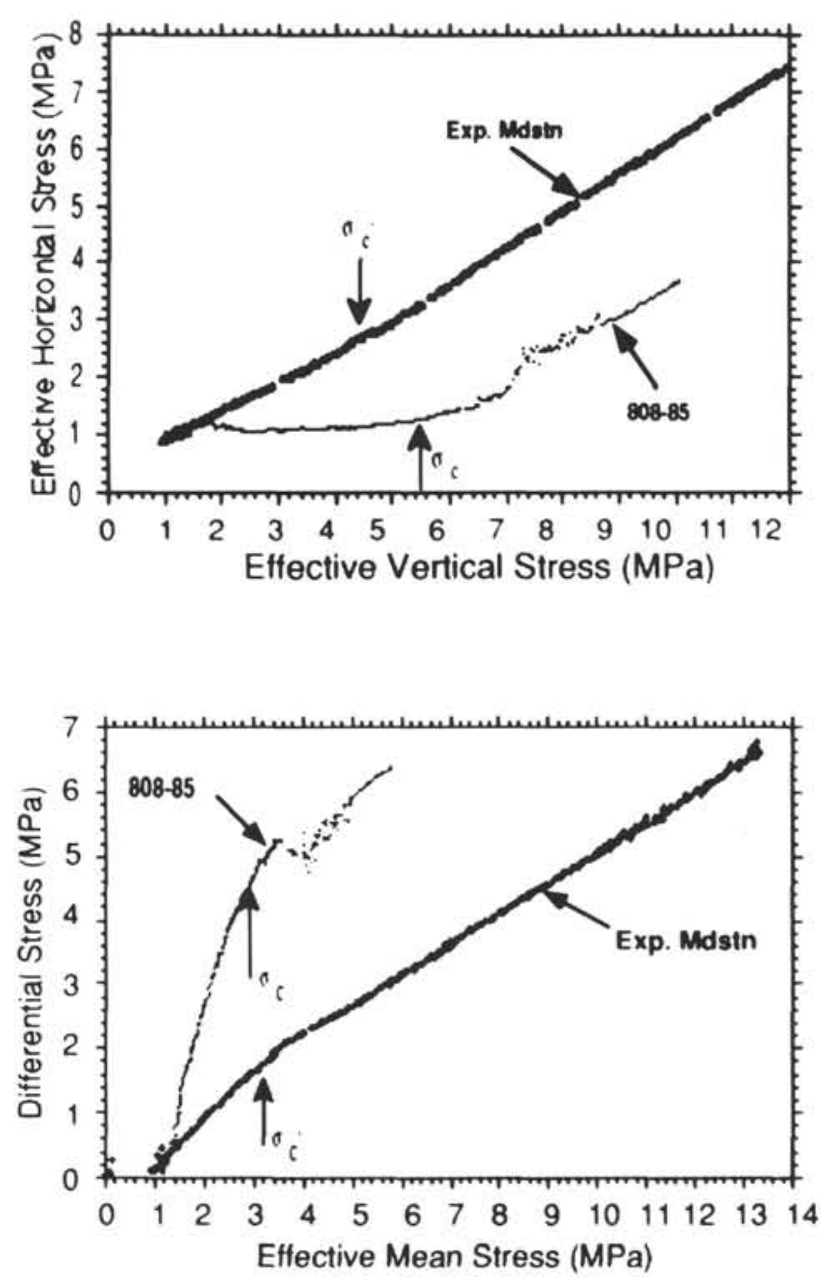
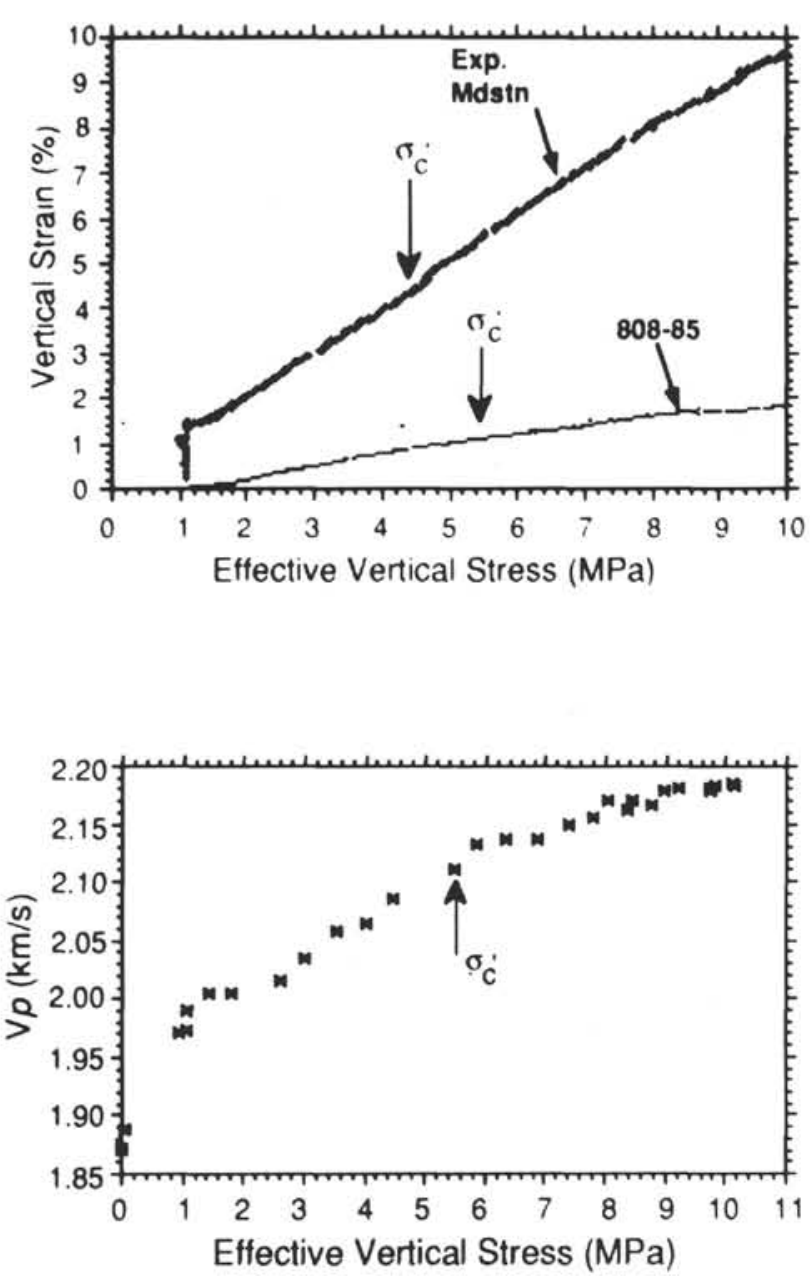

Figure 6. Representative relationships of mechanical parameters and physical properties for consolidation test (T-39) on Sample 582-85-1 and for a similar test on an analogous mudstone previously consolidated to $\sigma_{v}{ }^{\prime}=6 \mathrm{MPa}$.

For Sample $582-63, \sigma_{v h}^{\prime}$ is thus calculated to be about $5.6 \pm 0.2$ $\mathrm{MPa}$, which is significantly less than the estimated value of $\sigma_{c}^{\prime}=6.9$ $\mathrm{MPa}$. On the same basis, Sample 582-73 is more overconsolidated, with $\sigma_{v h}{ }^{\prime}=6.4 \pm 0.2 \mathrm{MPa}$ and $\sigma_{c}{ }^{\prime}=9.0 \pm 0.5 \mathrm{MPa}$.

In contrast to the overconsolidation suggested by $\sigma_{c}{ }^{\prime}$, the porosity of both samples tested from Site 582 are far greater than those of the experimentally consolidated mudstone or of typical mudstones at the same stress or depth (Fig. 9). These anomalously high porosities would imply that the samples from Site 582 were highly underconsolidated, with overpressures of about $6 \mathrm{MPa}$ for Core 582-63 and $8 \mathrm{MPa}$ for Core 582-73. If valid, this porosity-stress correlation also leads to values for $\sigma_{v^{*}}$ of about $2 \mathrm{MPa}$ at the sample depths.

This is not an anomaly restricted to the two samples tested, because most of the upper Shikoku Basin sequence at Site 582 displays these high porosities (Fig. 10, and Bray and Karig, 1986). Bray and Karig (1988) attributed the downward increase in porosity of about $5 \%$, from the base of the trench-fill strata into the Shikoku Basin hemipelagites, to a pore pressure gradient resulting from drainage of the overpressured hemipelagites into the more permeable trench-fill strata. However, this overpressure was estimated to be only about $1 \mathrm{MPa}$ above hydrostatic in the section from which the samples were recovered based upon an analysis using the consolidation equation (Bray and Karig, 1988).

The mechanical behavior of the samples from Site 582 at stress levels above the yield state was complex, as illustrated by plots of $\sigma_{h}{ }^{\prime}$ vs. $\sigma_{v}{ }^{\prime}$ and $\Delta \sigma$ vs. $\Delta_{m}^{\prime}$ (Fig. 7). Instead of showing simple, bilinear trends on the $\sigma_{h}{ }^{\prime}$ vs. $\sigma_{v}{ }^{\prime}$ plot, as do the experimental mudstones and those from Site 808 , the stress ratios for samples from Site 582 increase to values far above the $K_{0}$ value expected for a plastic response. The test on Core 582-63, which was continued to an axial stress far above $\sigma_{c}{ }^{\prime}$, showed that the stress ratio decreased to $K_{0}$ and remained constant as $\sigma_{v}{ }^{\prime}$ increased. In retrospect it is clear that the tests on Core 582-73 were not continued to high-enough values of $\sigma_{v}{ }^{\prime}$.

On plots of $\Delta \sigma$ vs. $\sigma_{m}{ }^{\prime}$, which have become a common method of illustrating stress paths for porous sediments, test results for samples from Site 582 show the stress paths to have risen far above that for $K_{0}$ consolidation before converging with the $K_{0}$ line (Fig. 7). Over the post-yield stress range there is also a sharp increase in $\varepsilon_{v}$ or equivalently, a decrease in porosity on these tests.

Such post-yield responses suggest that the samples from Site 582 have a component of strength in excess of that imparted by mechanical consolidation. Furthermore, this excess strength is apparently being destroyed in the post-yield stress range as the sample returns to a simple plastic response similar to that of the experimentally consolidated mudstone. This interpretation is supported by the large vertical creep and increase in $\sigma_{h}{ }^{\prime}$ during stress holds in the post-yield stress range, which also suggests breakdown of conditions supporting the excess strength.

This behavior, and the apparently contradictory consolidation states for the samples from Site 582, can be explained by the effect of "cementation" on the measured yield stress. In this sense cementation refers to processes such as secondary mineralization and electrochemical effects in clays as well as deposition of a matrix material and is equivalent to "structure" as used in geotechnical literature (e.g., Burland, 1990). In the samples from Site 582, cementation probably 

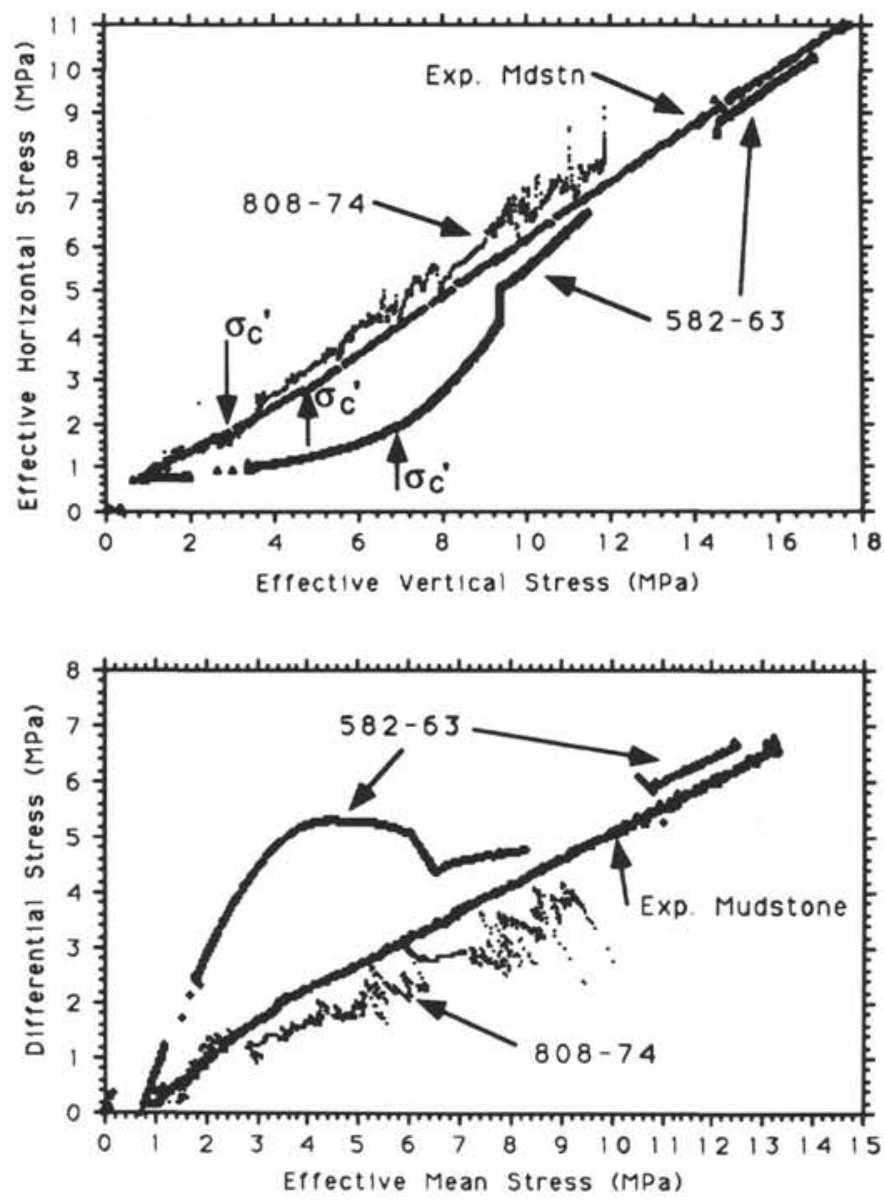

Figure 7. Comparative plots of $\Delta \sigma$ vs. $\sigma_{m}{ }^{\prime}$ and $\sigma_{h}{ }^{\prime}$ vs. $\sigma_{v}{ }^{\prime}$ for samples from Sites 582 and 808 and for an experimentally consolidated mudstone of similar mineralogy. These plots illustrate that the experimentally consolidated mudstone is quite similar in mechanical response during the elastic and post-yield stress paths to samples from Site 808, but is quite different from the samples from Site 582. All samples have remarkably similar stress paths when fully plastic.

results from secondary (authigenic) phyllosilicates at grain contacts (Knipe, 1986).

This cement increases the yield strength and stiffness of a sediment without significantly reducing its porosity. To some extent, cementation inhibits consolidation so that, even with hydrostatic pore pressure, porosities of natural mudstones, which are generally incipiently cemented, are somewhat higher than that of their experimentally consolidated analogs (Fig. 9). However, the samples from Site 582 have far higher porosities than typical mudstones at an equivalent $\sigma_{v h}{ }^{\prime}$ and must reflect some excess pore pressure. Thus, in these samples the effects of high pore pressure and of cementation oppose each other in affecting the yield stress, but the increase due to cementation has overcompensated for the reduction that should have resulted from the excess pore pressure. The opposing effects of high pore pressure and of cementation on $\sigma_{c}{ }^{\prime}$ are not separable by consolidation tests alone, but qualitative discrimination between them is provided by the shape of the stress path on plots of $\Delta \sigma$ vs. $\sigma_{m}{ }^{\prime}$.

In contrast to the behavior of samples from Site 582, samples from beneath the décollement at Site 808 show no excess strength attributable to cementation and show values of $\sigma_{c}{ }^{\prime}$ significantly less than $\sigma_{v h}{ }^{\prime}$. Core 131-808C-74R, taken at a depth of about $1000 \mathrm{mbsf}$, and $50 \mathrm{~m}$ beneath the décollement, has a $\sigma_{c}{ }^{\prime}$ of $2.9 \mathrm{MPa}$, whereas $\sigma_{v h}{ }^{\prime}$ at that position is about $9.2 \mathrm{MPa}$ (Fig. 5). Core 131-808C-85R was collected

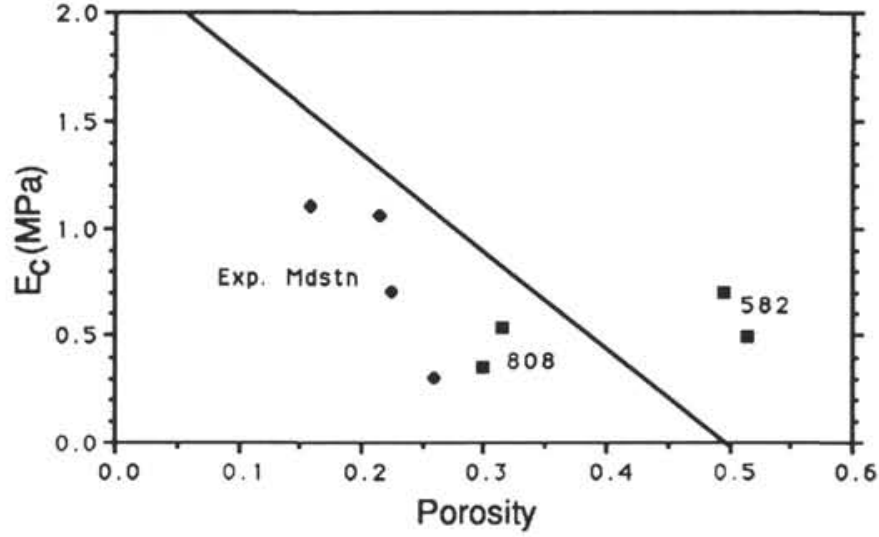

Figure 8. Plot of constrained modulus $\left(E_{\mathrm{c}}\right)$ vs. porosity $(\eta)$ for samples from Sites 582 and 808 and also from samples of experimentally consolidated mudstone (Karig and Hou, 1992). The diagonal line is a general relationship between $E_{\mathrm{c}}$ and $\eta$ derived from data of Evans et al. (1989) and Kulhawy (1975).

at a depth $100 \mathrm{~m}$ greater and shows less extreme apparent underconsolidation; $\sigma_{c}{ }^{\prime}$ for that sample was $5.5 \mathrm{MPa}$ in contrast to $\sigma_{v h}{ }^{\prime}$ of approximately $10.4 \mathrm{MPa}$ (Fig. 6).

Plots of results from both tests are qualitatively similar to those of the experimentally consolidated mudstone in that there were no anomalous responses in the post-yield stress range. The results from Core 131-808C-74R were even quantitatively similar to the experimental mudstone (Fig. 7). In addition, $E_{\mathrm{c}}$ for both these samples was only moderately greater than that of the experimental mudstone and far less than the extrapolated value for Site 582 (Fig. 8). These observations suggest a very low level of cementation in the samples tested from Site 808 and would imply that their underconsolidated state reflects high fluid pressures.

Ironically, the porosities of these samples are far less than those from Site 582 , both absolutely and relative to $\sigma_{v h}{ }^{\prime}$, as shown on a plot of porosity vs. $\sigma_{v}^{\prime}$ (Fig. 9). In comparison with a typical mudstone at the same $\sigma_{v h}{ }^{\prime}$, these samples are slightly underconsolidated, with overpressures of about $1 \mathrm{MPa}$, significantly less than are implied by $\sigma_{c}^{\prime}$.

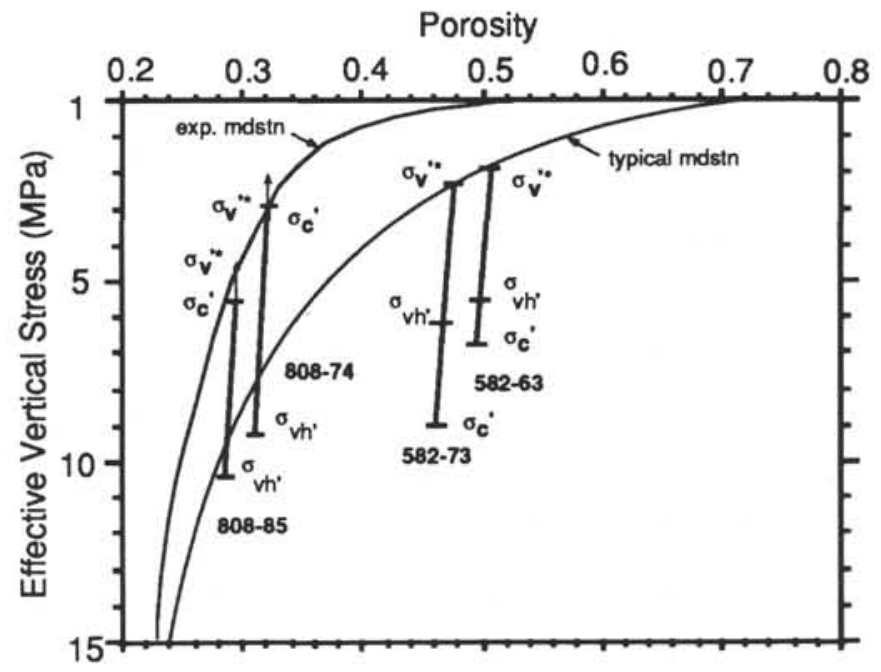

Figure 9. Porosity vs. $\sigma_{v}{ }^{\prime}$ for the samples from Sites 582 and 808 , for the experimentally consolidated mudstone (from Karig and Hou, 1992), and for typical natural mudstone sections (from Hamilton, 1979 and Busch, 1989). The bars for the test samples show the relationships among the observed $\sigma_{c}{ }^{\prime}$, the calculated $\sigma_{v h}{ }^{\prime}$ at the sample depth, and the estimated $\sigma_{v^{*}}{ }^{\prime}$, all at the appropriate porosities. 


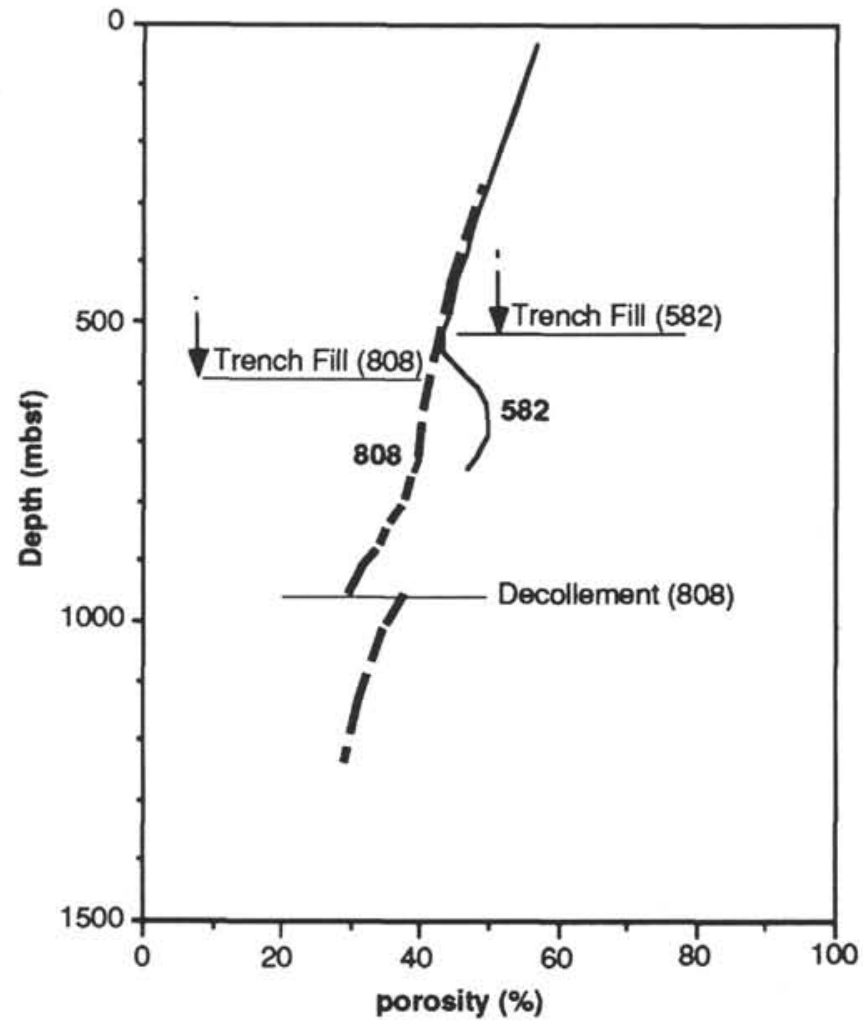

Figure 10. Porosity vs. depth relationships at Site 582 (from Bray and Karig, 1986) and Site 808 (from Taira, Hill, Firth, et al., 1991), with the positions of relevant geologic boundaries. The data are not corrected for porosity rebound and represent primarily mudstones.

Yet another possible estimate of the consolidation state beneath the décollement at Site 808 might be made by comparison of $\sigma_{v h}^{\prime}$ in these samples with that of mudstones above the décollement that have the same porosity (Fig. 10). The difference in $\sigma_{v h}{ }^{\prime}$ might then be attributed to the additional load from sedimentation and tectonic thickening after drainage from the lower strata had become blocked. If so, this difference in $\sigma_{v h}{ }^{\prime}$ would be equivalent to an excess pore pressure. Unfortunately, this approach is not valid because the sediments above the décollement have reached failure or at least have been subjected to higher differential stresses than those below. Such stress states result in lower porosities than do $K_{0}$ stresses at the same $\sigma_{m}{ }^{\prime}$ (e.g., Atkinson and Bransby, 1978; Karig, 1990). Thus to some as yet unquantified extent, the downward porosity increase across the décollement is a result of differing stress states, although higher pore pressure below that stress boundary is also a likely contributor.

The consolidation states derived from porosity data of the samples tested from Site 808 are, in reality, compatible with those based on measurements of $\sigma_{c}^{\prime}$ if the effects of both excess pore pressure and loss of cementation are considered. The porosity in Core 131-808C-85R, which is the easier of the two tests to explain, is compatible with hydrostatic consolidation to a depth of about $700 \mathrm{~m}$. This depth estimate would increase if higher pore pressures were assumed. This sample was recovered $150 \mathrm{~m}$ beneath the décollement, the tip of which propagates seaward at a depth of 600 to $650 \mathrm{~m}$ (Moore et al., 1991). Thus the porosity could be explained by hydrostatic or slightly higher pore pressures during consolidation until the sample passed beneath the tip of the décollement, at which point drainage effectively ceased. Cessation of drainage does not preclude flow of fluid beneath the décollement, but only that no net loss of fluid occur.

The depth of consolidation in Core 31-808 C-8SR implied by $\sigma_{c}{ }^{\prime}$, assuming hydrostatic pore pressure, is about the same or slightly less
$(600 \mathrm{~m})$ than that suggested by porosity. If this difference is not attributable merely to a lack of accuracy it could reflect slight "destructuring." Destructuring is the destruction of cementation, observed in some clays (Leroueil and Vaughan, 1990), that reduces $\sigma_{c}{ }^{\prime}$ toward that of a totally unstructured or uncemented sediment. Destructuring is attributed to natural or human-induced sample disturbance, or application of stress states below the yield state (Leroueil and Vaughan, 1990 ; Burland, 1990). If the $\eta-\sigma_{y}^{\prime}$ curve for typical natural mudstones can be assumed to be a reference for the mudstones at Site 808, Figure 9 indicates that the sample from Core $131-808 \mathrm{C}-85 \mathrm{R}$ may have been slightly destructured.

The consolidation of the sample from Core 131-808C-74R can be explained in a similar manner, but a much greater degree of destructuring is implied. The estimation of depth at maximum consolidation based on porosity is about $600 \mathrm{~m}$, again a bit shallower than the depth of the tip of the décollement plus the depth of the sample below the décollement, and could reflect some overpressure before drainage was blocked. The value of $2.9 \mathrm{MPa}$ for $\sigma_{\mathrm{c}}{ }^{\prime}$ is compatible with the observed porosity (Fig. 9) if destructuring were effectively complete, as is suggested by the lack of cementation reflected in the test results (Figs. 5 and 7).

The destructuring of samples from Site 808 is not thought to be a result of handling because samples from Site 582, which had been stored for many years, showed no such destructuring. It is more likely that the destructuring,was natural, such as might have been produced by isotropic stress oscillations (Leroueil and Vaughan, 1990). The oscillations might have been caused by pulses of pore fluid moving along the décollement and diffusing outward. This scenario could also explain why destructuring is more nearly complete for the sample closer to the décollement.

Whatever the cause for destructuring, if it has occurred naturally in the samples from $\mathrm{Site} 808, \sigma_{c}{ }^{\prime}$ from the tests provide upper bounds for $\sigma_{v^{*}}$ (Fig. 9). No lower bound for $\sigma_{v^{*}}$ ' can be deduced from the experimental data because the minimum value of $\sigma_{c}{ }^{\prime}$ possible is that associated with a totally unstructured, uncemented mudstone; pore pressures could be even higher, and thus $\sigma_{v}{ }^{\prime}$ lower, leaving no permanent record in the sediment.

\section{Plastic Regime}

A plastic or "virgin" response seems to have been generated during both tests at Site 808 and the test on Core $582-63$ as marked by constant stress ratios, or $K_{0}$ values. $K_{0}$ ranged from 0.60 to 0.68 in these tests (Figs. 3, 5, and 6) and compares closely with the 0.62 to 0.64 values for the experimentally consolidated mudstone (Fig. 7). Such $K_{0}$ values are typical for mudstones and shales and appear to be constant over a large range of applied vertical stress (Karig and Hou, 1992).

On the other hand, the porosities of the samples from Site 582, particularly the sample from Core 582-63, which is assumed to behave plastically, are still far greater than those of the experimentally consolidated mudstone at the same stress levels (Fig. 9). One probable cause of this difference is that only the central sections of the samples have become fully plastic because of the frictional "end effects" of the platens (Peng, 1971). The rapid, quasilinear vertical strain observed during the final stages of this test also suggests that porosities were decreasing toward those of their uncemented analogs (Fig. 3). Support for the validity of the observed $K_{0}$ values despite this porosity behavior is provided by stress holds in this regime, which show no change in $\sigma_{h}^{\prime}$ but significant vertical strain.

Determination of the in-situ value of $\sigma_{h}{ }^{\prime}$ remains an important objective in the study of stress in the crust. Even for the simple case of uniaxial consolidation, as approximated in basins, $\sigma_{h}{ }^{\prime}$ and $K_{0}$ are not well constrained. Estimates of $\sigma_{h}{ }^{\prime}$ at the in-situ value of $\sigma_{v}{ }^{\prime}$ from the tests on samples from Sites 582 and 808 might provide an estimate of the in-situ value of $\sigma_{h}^{\prime}$. Values of $\sigma_{h}^{\prime}$ at $\sigma_{c}^{\prime}$ during reconsolidation tests on the experimentally consolidated mudstone are very close to those during the initial consolidation. However, there is a serious 
question as to whether or not sediments, especially clays, behave viscoelastically over geologic time and tend toward an isotropic stress state (e.g., Warpinski et al., 1985). Moreover, the effect of cementation on $K_{0}$ is not known. The values of $\sigma_{h}{ }^{\prime}$ at $\sigma_{c}{ }^{\prime}$ for all the samples tested from the Nankai Trough are significantly less than $K_{0}$, with the value for the sample from Core 131-808C-73R being the highest $(0.55)$. Thus, if viscoelastic effects were not significant, cementation during consolidation would appear to reduce the value of $K_{0}$, but this assumption must still be justified by in-situ testing.

\section{Porosity Rebound}

Porosity rebound has been an important but seldom analyzed factor in relating lab data to in-situ or logging values. Logging values of $\eta$ have tended to be accepted as accurate (e.g., Nobes, 1991, Jarrard et al., 1989), but these can be significantly affected by the assumed grain density and mineralogy (e.g., Plumb et al, 1991). Until such effects are better evaluated, it would seem judicious to compare logging values with rebound-corrected shipboard values of $\eta$.

Porosity rebound for experimentally consolidated, uncemented mudstones increases with increasing $\sigma_{c}{ }^{\prime}$ and approaches $10 \%$ at $\sigma_{c}{ }^{\prime}$ of $35 \mathrm{MPa}$ (Karig and Hou, 1992). The most commonly cited data set for naturally consolidated mudstones is that of Hamilton (1976), which shows rebound to rise to more than $9 \%$ near $\sigma_{c}{ }^{\prime}=5 \mathrm{MPa}$ and then decrease with increasing $\sigma_{c}^{\prime}$ (Fig. 11). This pattern of porosity rebound was interpreted as the combined result of elastic and inelastic volume increase, with the elastic component decreasing as Young's modulus increases (Karig and Hou, 1992). Thus, increasing cementation will decrease the elastic rebound, although its effect on the inelastic component is not well known.

Porosity rebound for all the natural samples of the test series was far less than those found by Hamilton (1976). Rebound values depend on the validity of the estimated $\sigma_{y^{*}}{ }^{\prime}$, but because porosity changes very slowly between the crack-closing stress $(\sim 1 \mathrm{MPa})$ and $\sigma_{c}{ }^{\prime}$, even a general estimate of the in-situ stress is sufficient for an adequate rebound value. Samples from Site 582 have rebound values of $<1 \%$, whereas those from Site 808 have values of about $2 \%$. The reason for the large differences between these and the values of Hamilton (1976) will require further careful measurements of both rebound and associated elastic moduli of natural mudstones.

\section{Seismic Velocities}

The velocity of seismic waves in porous sediments are dependent on the porosity, lithology, and elastic moduli of those sediments. Seismic velocities are also affected by pressure at which the measurements are made, and shipboard values should be corrected before comparison with log or other in-situ velocity measurements.

Measurements of $V_{p}$ in our lab during tests having various stress paths have indicated that $V_{p}$ is primarily responsive to stress in the direction of wave propagation, which is $\sigma_{v}{ }^{\prime}$ in this study. $V_{p}$ in all our tests increased sharply with increased axial stress at low stresses (from $0 \mathrm{MPa}$ to 2 or $3 \mathrm{MPa}$ ). This is a widely observed phenomenon and is attributed to closing of microcracks (e.g., Bourbie et al., 1987). Plots of $V_{p}$ vs. $\sigma_{v}{ }^{\prime}$ for uncemented, experimentally consolidated mudstone show a single quasilinear relationship through that part of the elastic regime above the crack-closing stress into the plastic, consolidation regime (Fig. 12). For the sample from Core 131-808C$85 \mathrm{R}$, the slope of $V_{p} / \sigma_{v}{ }^{\prime}$ appears to decrease slightly throughout this range. Velocities are lower than for the experimental mudstone, reflecting the effect of the higher porosity of samples from Site 808, but the basic $V_{p}-\sigma_{v}{ }^{\prime}$ patterns are similar.

The measurements on samples from Site 582, on the other hand, show a bilinear relationship, with a lower $V_{p} / \sigma_{v}{ }^{\prime}$ slope through the elastic regime (above the crack-closing stress range) and slightly into the plastic regime (Fig. 12). Over the rest of the plastic regime tested, this slope became significantly higher.

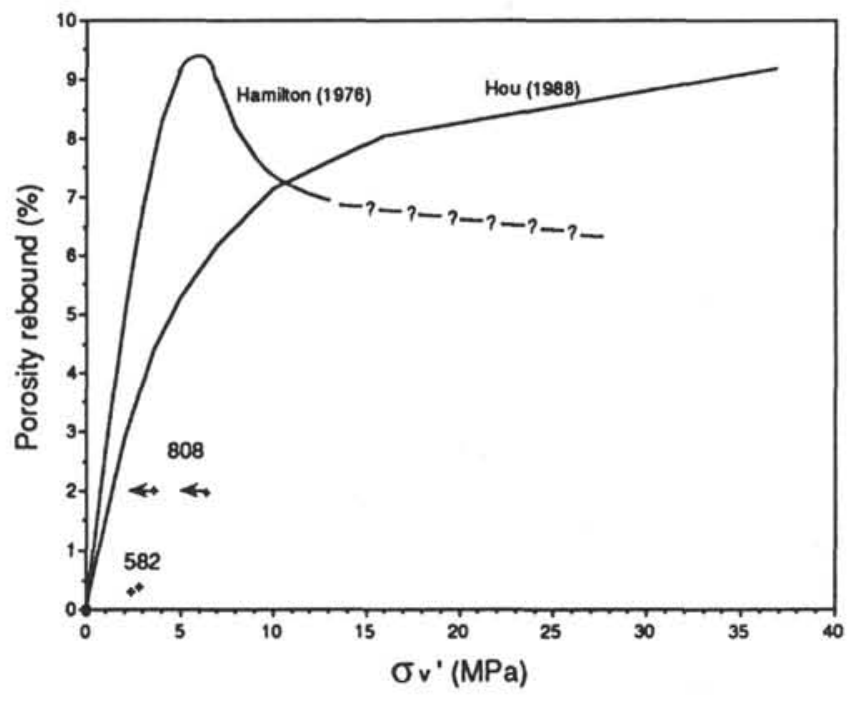

Figure 11. Porosity rebound for samples of this test series together with rebound curves for natural mudstones from Hamilton (1976) and for the experimentally consolidated mudstone from Karig and Hou (1992). Rebound for the samples is taken from the estimated $\sigma_{v^{\prime}}{ }^{\prime}$ rather than from $\sigma_{c}^{\prime}$, but the differences are small. The arrows on the data points for Site 808 reflect the possibility that the tests provide only upper bounds for $\sigma_{v}^{\prime}$.

Another perspective on the seismic velocities is obtained from $V_{p}-\eta$ plots of individual tests (Fig. 13). The samples from Site 808 and those consolidated experimentally show near-linear curves with slopes of $\eta$ vs. $V_{p}$ near $0.11 \mathrm{~s} / \mathrm{km}$ over the entire stress range investigated. The samples from Site 582 , on the other hand, show a sharp increase in slope at or near $\sigma_{c}{ }^{\prime}$. At stresses below $\sigma_{c}{ }^{\prime}$, the slope is very small $(0.02 \mathrm{~s} / \mathrm{km})$ and constant, even in the crack-closing regime, but above $\sigma_{c}{ }^{\prime}$ this slope increases dramatically.

Clearly $V_{p}$ in these mudstones is responding to some factor other than $\eta$, and this factor is most likely the component of elastic stiffness induced by cementation. In the stress range of elastic response, the higher values of $E$ in the samples from Site 582 produce similar velocities at higher porosities, or conversely, much higher velocities at similar porosities. Furthermore, the velocities in the cemented samples increase faster with decreasing porosity, reflecting the dominance of increasing elastic stiffness over decreasing porosity and density. Most likely, the apparent decrease in the dependence of $V_{p}$ on $\eta$ at stresses above $\sigma_{c}{ }^{\prime}$ in the samples from Site 582 reflects the destruction of cementation during deformation through the plastic regime and loss of the cementation-induced stiffness. This loss of cementation would also account for the more rapid decrease in $\eta$ seen in these samples in the plastic regime. This more rapid reduction in $\eta$, on the other hand, does cause a more rapid increase in velocity when plotted against $\sigma_{y}^{\prime}$ (Fig. 13).

The increase in $V_{p}$ from lab conditions to $\sigma_{c}{ }^{\prime}$ ranged from 0.18 to $0.25 \mathrm{~km} / \mathrm{s}$ (Table 1). The corrections to the estimated in-situ stress are about $0.10 \mathrm{~km} / \mathrm{s}$ for samples from Site 582 and $0.20 \mathrm{~km} / \mathrm{s}$ for the sample from Core 131-808C-85R. These velocity measurements provide a pressure correction for the shipboard measurements toward their in-situ values, but do not take into account possible effects of the difference in temperature between laboratory and in-situ conditions. Such temperature corrections are usually assumed to be much smaller than the pressure corrections and in the opposite direction (Bourbie et al., 1987; Timur, 1977), but the $V_{p}$ data of Leg 131 (Taira, Hill, Firth et al., 1991) were presented with large positive temperature corrections. The apparent assumption behind these corrections is that the increase in $V_{p}$ of the saline pore fluid with temperature (e.g., Mackenzie, 1981) dominates the effect.

There is very little information available concerning the effect of temperature on $V_{p}$ in sediments of high $(>25 \%)$ porosity. Measure- 


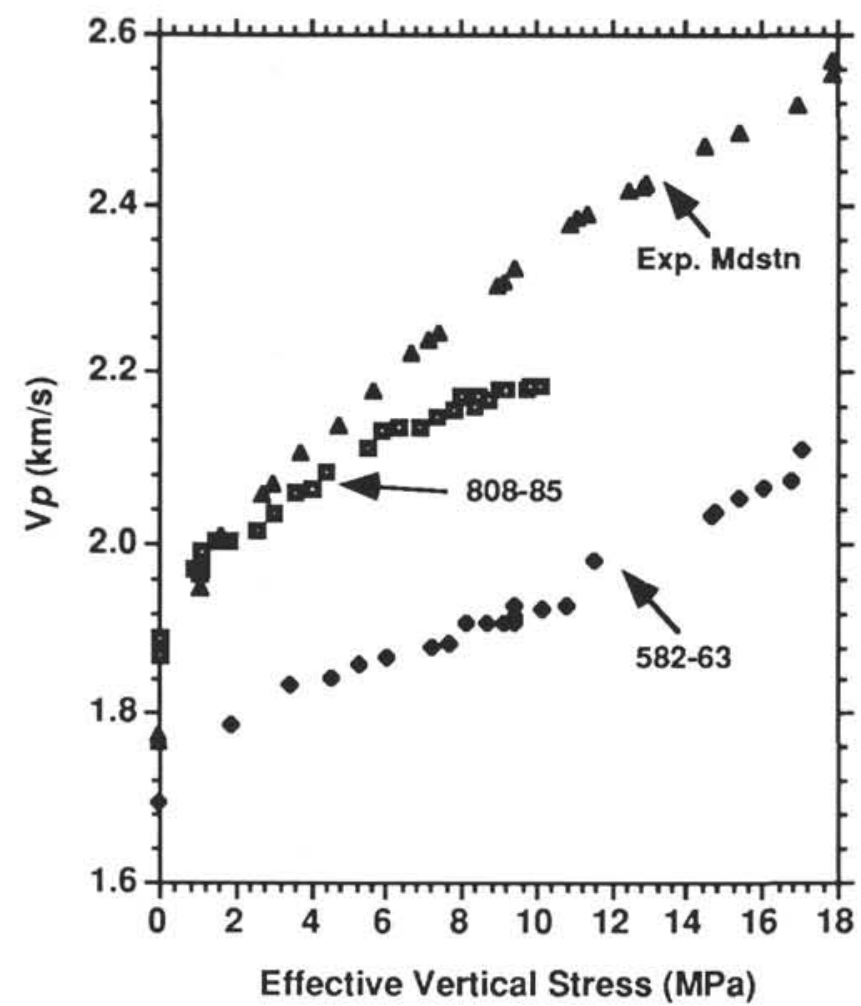

Figure 12. Comparative $V_{p}$ vs. $\sigma_{v}{ }^{\prime}$ data from tests on samples from Sites 582 and 808 , and from the experimentally consolidated mudstone. Velocities were measured in the vertical direction.

ments by Timur (1977) and Wang and Nur (1990) are the most applicable and show that an increase in temperature decreases $V_{p}$ in the mineral component but that this effect decreases with an increase in porosity. There are no data for mudstones of high porosities, but sandstones with porosities as high as $37 \%$ still have a moderately negative temperature correction (Wang and Nur, 1990).

Values of $V_{p}$ at the estimated in-situ stress provide information for construction of a velocity-porosity relationship, which not only permits estimation of in-situ porosity from seismic data, but also reveals more about the effect of cementation on the elastic properties of the sediment. Despite the present paucity of data points, there is a clear difference in the velocity-porosity relationships between the samples from Sites 582 and 808 . The estimated in-situ $V_{p}$ for the samples from Site 582 lie on or slightly above the $\eta$ vs. $V_{p}$ curve of Hamilton (1978), which appears to be applicable to natural mudstones (Fig. 14). An in-situ $V_{p}$ from Core 131-808C-85R as well as one from a test using Core $131-808 \mathrm{C}-74 \mathrm{R}$ that was aborted before reaching $\sigma_{c}{ }^{\prime}$ both lie well below the Hamilton curve. From the few seismic data from the tests it would appear that the mudstones from Site 582 are more nearly typical than are those from beneath the décollement at Site 808, in agreement with the mechanical responses of these samples.

\section{DISCUSSION AND SPECULATIONS}

The results of this series of tests on mudstones from the Nankai Trough have implications both for the state of stress at Site 808 and for the mechanical behavior of natural mudstones in general. Although the test results do not provide unambiguous values of the in-situ vertical stress they do offer constraints, not only for the stress path during consolidation in the trench wedge but also for that part of the path followed by the sediments as they pass beneath the décollement. The basic assumption in this exercise is that the behavior of the natural mudstones of the tests can be compared with that of typical

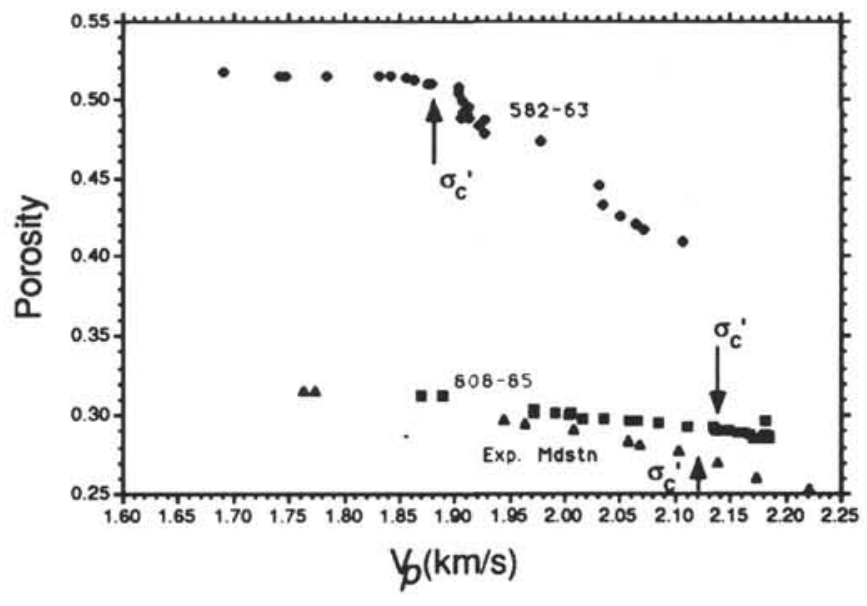

Figure 13. Comparative $V_{p}$ vs. $\eta$ data from tests on samples from Sites 582 and 808 , and from the experimentally consolidated mudstone. Velocities were measured in the vertical direction.

mudstones, and that our experimentally consolidated mudstone can be viewed as a destructured reference sediment for all the natural mudstones. Aspects of this broad assumption are supported by the similarity of the test samples with the experimental analog over the plastic stress path and by at least some similarities between samples from Site 582 and typical mudstones.

The evidence for fluid overpressure at Site 582 suggests that the consolidation of the relatively impermeable Shikoku Basin mudstones is associated with pore pressures well above hydrostatic. The overpressure at the depths of the two samples can be estimated if the porosity- $\sigma_{y}{ }^{\prime}$ relationship for typical natural mudstones can be used as a reference; from these estimates the relative overpressure can be calculated.

Overpressures at Site 582 increase downward from about $5 \mathrm{MPa}$ at $644 \mathrm{mbsf}$ to about $6 \mathrm{MPa}$ at $744 \mathrm{mbsf}$. Although these values are significantly greater than those found using solutions to the consolidation equation (Bray and Karig, 1988), those solutions also involve serious assumptions. The downward increase in overpressure is logical if the boundary with the overlying, more highly permeable trenchfill strata permits easy upward drainage.

The relative overpressure, or $\lambda$ (using the definition of Davis et al., 1983), is

$$
\lambda=\left(g \rho_{w} \Delta z+\text { Overpressure }\right) / \Sigma_{g} \rho_{b} \Delta z
$$

For Core 582-63 at $644 \mathrm{mbsf}, \lambda \sim 0.85$, and for Core $582-73, \lambda \sim$ 0.83 . These values are probably upper bounds, whereas the 0.6 to 0.65 values of Bray and Karig (1988) might be close to a lower bound, if these samples were anomalously well cemented. In any case, the upper Shikoku mudstones at Site 582 are almost certainly overpressured.

It is not clear whether consolidation of the Shikoku Basin mudstones at Site 808 beneath the load of the trench-fill was accompanied by similar overpressures. The porosity of these samples is much lower than that Site 582, even after the effects of tectonic thickening and differences in depth at maximum consolidation stress are taken into account. Furthermore, when these effects are removed, the porosities of the samples from Site 808 are much like those of typical natural mudstones at similar depths (Figs. 9, 15). Both observations suggest that overpressures were much less than at Site 582 during loading by the trench-fill, although there is no obvious reason why this should be so.

The samples from below the décollement at Site 808 represent points now further along the stress path, and show evidence of large fluid overpressure (Fig. 15). The constant thickness and velocity through the section beneath the décollement from the tip to Site 808 (Moore et al., 1991) argues for an effectively undrained behavior 


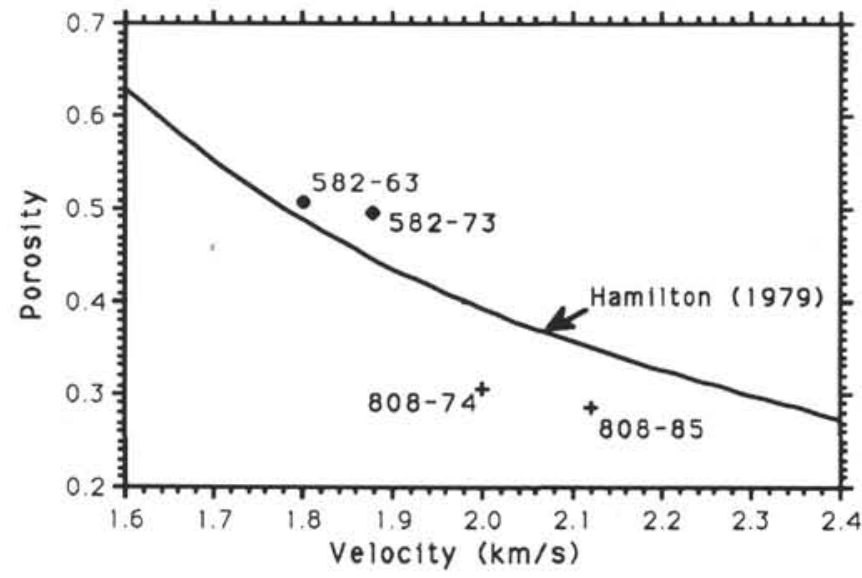

Figure 14. Seismic velocity vs. estimated in-situ porosity data from tests on samples from Sites 582 and 808 , together with the $V_{p}$ vs. $\eta$ relationship for mudstone sections from Hamilton (1979).

(Fig. 15). If this were the only effect on the pore fluid, then, despite the increase in $\sigma_{v} \sigma_{v^{*}}$ ' would remain unchanged, and without cementation, $\sigma_{c}{ }^{\prime} \sim \sigma_{y^{*}}{ }^{\prime}$. This is approximately the case for the deeper of the two samples, where $\sigma_{c}{ }^{\prime}$ is only slightly less than $\sigma_{v h}{ }^{\prime}$ would be for a depth about $150 \mathrm{~m}$ beneath the tip of the décollement.

For the sample from Core 131-808C-74R, however, $\sigma_{c}{ }^{\prime}$ is far less than $\sigma_{v h}{ }^{\prime}$ at the equivalent depth beneath the tip. This low value is interpreted as an effect of destructuring, or destruction of cement by sub-yield stress oscillations. These oscillations could possibly be variations in pore-fluid pressure, caused by pulses of high-pressure fluid traveling up the décollement and diffusing outward (Karig, et al., 1990).

Values of $\lambda$ can be calculated from the two tests at Site 808 , but these would be minimal, for the reasons discussed earlier. For the sample from Core 131-808C-85R, $\lambda \geq 0.75$, and for the sample from Core $131-808 \mathrm{C}-74 \mathrm{R}, \lambda \geq 0.90$. It is quite likely that $\lambda$ becomes even greater toward the décollement and may approach 1.0 in that zone. This would explain the apparent complete stress discontinuity across the décollement.

The behavior of vertically propagated $V_{p}$ in this test series also reflects the differences in mechanical response between samples from the two sites, due largely to differences in "cementation." As has been recognized elsewhere (e.g., Hamilton, 1979), very subtle cementation can greatly increase seismic velocities in mineralogically uniform strata without significantly affecting porosity. This effect not only calls for caution in application of a single velocity-porosity function to a region, but it also implies that local variations in cementation can create velocity contrasts and anomalies.

In conclusion, these tests have illustrated the complex mechanical behavior of naturally consolidated mudstones in contrast to that of their experimentally consolidated analogs. Elucidation of these complexities requires more care in the design of test programs and in data analysis than has generally been the case for reconsolidation tests in the ODP. In particular, conventional uniaxial consolidation (odometer) tests without measurements of $\sigma_{h}{ }^{\prime}$ are seriously limited in their ability to discriminate between the effects of cementation and fluid overpressure on $\sigma_{c}{ }^{\prime}$. This problem is exacerbated for low porosity, less cemented sediments for which the slope-break marking $\sigma_{c}^{\prime}$ on plots of $\varepsilon_{v}$ vs. $\sigma_{v}{ }^{\prime}$ can be extremely difficult to discern.

Despite the lack of success in the downhole measurements program at Site 808 , the structural, physical properties, and experimental deformation data on cores has been able to provide some constraints on the mechanical behavior at the toe of the Nankai prism. Correlation and integration of these post-cruise investigations should further tighten these constraints. These studies will certainly allow future

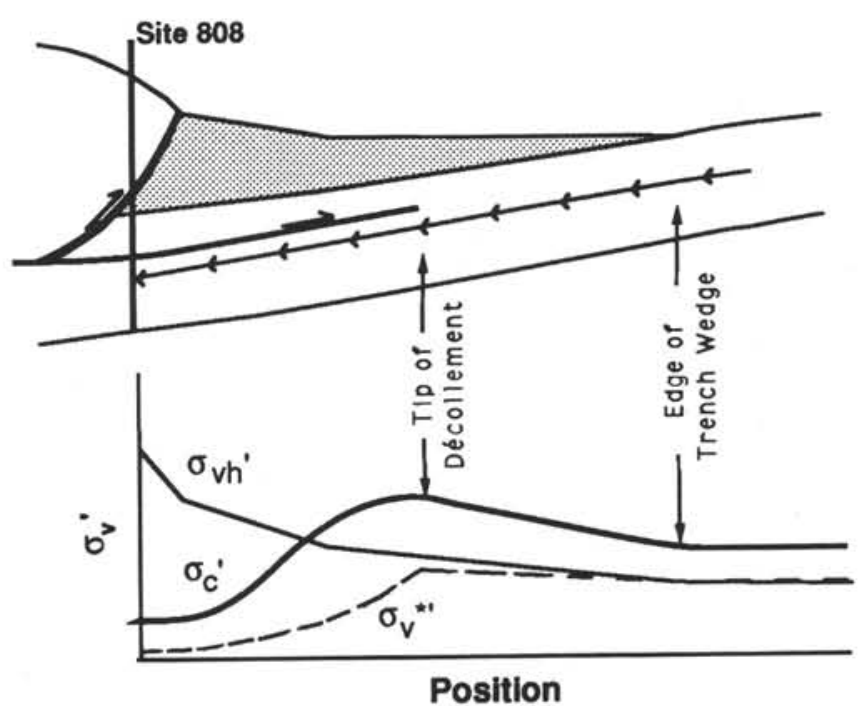

Figure 15. Summary diagram of vertical stresses along the flow line followed by test samples $808-74$ beneath the décollement to Site 808 . The graph conceptually shows the interpreted changes in $\sigma_{c}{ }^{\prime}, \sigma_{v h}{ }^{\prime}$, and $\sigma_{v^{*}}$ along the flow line.

investigations of this fascinating tectonic environment to be better focused and more efficient.

\section{ACKNOWLEDGMENTS}

I particularly appreciate the engineering support from George Hade, without whom the test equipment wouldn't have functioned. Cindy Bray and Juli Morgan helped respectively in developing software and in monitoring tests. Mike Underwood graciously ran the XRD analyses of the samples and, finally, Kevin Brown and Terry Miller provided critical and useful reviews of the manuscript. The work was supported by funds from the National Science Foundation through the U.S. Science Support Program associated with the Ocean Drilling Program and NSF Grant EAR8720754.

\section{REFERENCES}

Atkinson, J.H., and Bransby, P.L., 1978. The Mechanics of Soils: An Introduction to Critical State Soil Mechanics: London (McGraw-Hill).

Bourbié, T., Coussy, O., and Zinszner, B., 1987. Acoustics of Porous Media: Inst. Fr. Pet. Publ.

Bray, C.J., and Karig, D.E., 1986. Physical properties of sediments from the Nankai Trough, DSDP Leg 87A, Sites 582 and 583. In Kagami, H., Karig, D.E., Coulbourn, W.T., et al., Init. Repts. DSDP, 87: Washington (U.S. Govt. Printing Office), 827-842.

1988. Dewatering and extensional deformation of the Shikoku hemipelagic sediments in the Nankai Trough. Pure Appl. Geophys., 128:725-747.

Burland, J.B., 1990. On the compressibility and shear strength of natural clays. Geotechnique, 40:329-378.

Busch, W.H., 1989. Patterns of sediment compaction at Ocean Drilling Sites 645, 646, and 647, Baffin Bay and Labrador Sea. In Srivastava, S.P., Arthur, M., and Clement, B., et al., Proc. ODP, Sci. Results, 105: College Station, TX (Ocean Drilling Program), 781-790.

Davis, D.M., Suppe, J., and Dahlen, F.A., 1983. Mechanics of fold and thrust belts and accretionary wedges. J. Geophys. Res., 88:1153-1172.

Evans, K.F., Oertel, G., and Engelder, T., 1989. Appalachian stress study. 2. Analysis of Devonian shale core: some implications for the nature of contemporary stress variations and Alleghenian deformation in Devonian Rocks. J. Geophys. Res., 94:7154-7170.

Hamilton, E.L., 1976. Variations of density and porosity with depth in deep-sea sediments. J. Sediment. Petrol., 46:280-300. 
1978. Sound velocity-density relations in sea-floor sediments and rocks. J. Acoust. Soc. Am., 63:366-377.

1979. Sound velocity gradients in marine sediments. J. Acoust. Soc. Am., 65:909-922.

Jamiolkowski, M., Ladd, C.C., Germaine, J.T., and Lancellotta, R., 1985. New developments in field and laboratory testing of soils. Proc. 11th Int. Conf. on Soil Mech. and Foundation Eng., 1:57-153.

Jarrard, R.D., Dadey, K.A., and Busch, W.H., 1989. Velocity and density of sediments of Eirik Ridge, Labrador Sea: control by porosity and mineralogy. In Srivastava, S.P., Arthur, M.A., Clement, B., et al., Proc. ODP, Sci. Results, 105: College Station, TX (Ocean Drilling Program), 811-835.

Karig, D.E., 1990. Experimental and observational constraints on the mechanical behaviour in the toes of accretionary prisms. In Knipe, R.J., and Rutter, E.H. (Eds.), Deformation Mechanisms, Rheology, and Tectonics. Geol. Soc. Spec. Publ. London, 54:383-398.

Karig, D.E., and Hou, G., 1992. High-stress consolidation experiments and their geologic implications. J. Geophys. Res., 97:289-300.

Karig, D.E., Moran, K., and Leg 131 Scientific Party, 1990. A dynamically sealed décollement: Nankai Prism. Eos, 71:1626-1627.

Knipe, R.J., 1986. Faulting mechanisms in slope sediments: examples from Deep Sea Drilling Project cores. Mem.-Geol. Soc. Am. Mem., 166:45-54.

Kulhawy, F.H., 1975. Stress deformation properties of rock and rock discontinuities. Eng. Geol., 9:327-350.

Ladd, C.C., Foott, R., Ishihara, K., Schlosser, F., and Poulos, H.G., 1977. Stress-deformation and strength characteristics. Proc. 9th Int. Soil Mech. Conf. Tokyo, 2:421-494.

Lambe, T.W., 1951. Soil Testing for Engineers: New York (Wiley and Sons).

Lerouiel, S., and Vaughan, P.R., 1990. The general and congruent effects of structure in natural soils and rocks. Geotechnique, 40:467-488.

Lundberg, N., and Karig, D.E., 1986. Structural features from the Nankai Trough lower slope, DSDP Sites 582 and 583. In Kagami, H., Karig, D.E., Coulbourn, W.T., et al., Init. Repts. DSDP, 87: Washington (U.S. Govt. Printing Office), 797-808.
Mackenzie, K.V., 1981. Nine-term equation for sound speed in the oceans. J. Acoust. Soc. Am., 70:807-812.

Moore, G.F., Karig, D.E., Shipley, T.H., Taira, A., Stoffa, P.L., and Wood, W.T., 1991. Structural framework of the ODP Leg 131 area, Nankai Trough. In Taira, A., Hill, I., Firth, J.V., et al., Proc. ODP, Init. Repts., 131: College Station, TX (Ocean Drilling Program), 15-20.

Nobes, D.C., Mwenifumbo, C.J., Mienert, J., and Blangy, J.P., 1991. The problem of porosity rebound in deep-sea sediment cores: A comparison of laboratory and in-situ physical property measurements, Site 704, Meteor Rise. In Ciesielski, P.F., Kristoffersen, Y., et al., Proc. ODP, Sci. Results, 114:711-716.

Peng, S.D., 1971. Stresses within elastic circular cylinders loaded uniaxially and triaxially. Int. J. Rock Mech. Min. Sci., 8:399-432.

Plumb, R.A., Evans, K.F., and Engelder, T., 1991. Geophysical log responses and their correlation with bed-to-bed stress contrasts in Paleozoic rocks, Appalachian Plateau, New York. J. Geophys. Res., 96:14509-14528.

Taira, A., Hill, I., Firth, J.V., et al., 1991. Proc. ODP, Init. Repts., 131: College Station, TX (Ocean Drilling Program).

Timur, A., 1977. Temperature dependence of compressional and shear wave velocities in rocks. Geophysics, 42:950-956.

Wang, Z., and Nur, A., 1990. Wave velocities in hydrocarbon-saturated rocks: experimental results. Geophysics, 55:723-733.

Warpinski, N.R., Branagan, P., and Wilmer, R., 1985. In-situ stress measurements at U.S. DOE's Multiwell Experiment Site, Mesaverde Group, Rifle, Colorado. J. Pet. Tech., 37:527-536.

Date of initial receipt: 30 September 1991

Date of acceptance: 29 April 1992

Ms 131SR-127 